Article

\title{
Application of Dissolved Gas Analysis in Assessing Degree of Healthiness or Faultiness with Fault Identification in Oil-Immersed Equipment ${ }^{\dagger}$
}

\author{
George Kimani Irungu * (D) and Aloys Oriedi Akumu \\ Department of Electrical Engineering, Tshwane University of Technology, Pretoria West Private Bag X680, \\ Pretoria 0001, South Africa; akumuao@tut.ac.za \\ * Correspondence: irunguGK@tut.ac.za \\ † Note: this is a beef up of our conference paper titled "Comparison of IEC60599 gas ratios and an integrated \\ Fuzzy-Evidential reasoning approach in fault identification using dissolved gas analysis". 51st Intern. \\ Universities Power Engineering Conf. (UPEC), Coimbra Portugal, 2016, pp. 205-211. \\ doi:10.1109/UPEC20168114055. Available: http://ieeexplore.ieee.org.
}

Received: 3 August 2020; Accepted: 25 August 2020; Published: 12 September 2020

check for updates

\begin{abstract}
The healthiness and or faultiness of oil-immersed electrical equipment using dissolved gas characterization has remained a critical and challenging task in power systems. Dissolved gas analysis (DGA) continues to be the utmost preferred technique of detecting mainly slow evolving thermal and electrical faults. However, DGA can reveal more than just faults in equipment. This research looks at broad areas where DGA can be applied to determine the healthiness or faultiness of equipment in addition to fault identification. In equipment considered normal-i.e., fault-free-DGA can give the degree of healthiness (DOH) based on Rogers ratios $\mathrm{C}_{2} \mathrm{H}_{2} / \mathrm{C}_{2} \mathrm{H}_{4}<0.1,0.1<\mathrm{CH}_{4} / \mathrm{H}_{2}<1$, and $\mathrm{C}_{2} \mathrm{H}_{4} / \mathrm{C}_{2} \mathrm{H}_{6}<1$, plus the $3<\mathrm{CO}_{2} / \mathrm{CO}<10$ ratio for identifying fault-free devices. This answers the question: How healthy or normal is the equipment? Similarly, when these ratios are violated, it signifies the presence of faults, and two things ought to be determined. One is to identify the type of fault(s), which has been the norm. The other thing that can be evaluated is the degree of faultiness (DOF), based on the extent to which the ratios have been violated. Rarely has this been done. This might answer the question for the same fault class: How severe is the fault? To synthesize the DOH and/or DOF, fuzzy logic is applied. To diagnose faults, fuzzy logic and fuzzy-evidential tools are proposed. The accuracy and effectiveness of the proposed fuzzy techniques are better than those of the IEC60599 and Rogers methods, and they are comparable to those of the Duval Triangle 1 and Pentagon 1 methods using the six IEC faults. Results from DOF evaluation have shown electrical faults to be more impactful relative to the rest.
\end{abstract}

Keywords: degree of faultiness (DOF); degree of healthiness (DOH); dissolved gas analysis (DGA); evidential reasoning criterion; fault diagnosis; fuzzy logic (FL); fuzzy characterization curves; probability value assignments (PVAs)

\section{Introduction}

During the lifetime of oil-immersed electrical equipment, the oil-paper insulation system experiences a hostile operating electrical, thermal, and chemical environment. Such an environment makes the insulation system partially decompose, generating various gases that characterize the sources behind their origin. The extraction of these gases from oil remains the most effective, dependable, and worldwide technique for diagnosing excessive thermal and electrical operating stresses in electrical equipment [1-9]. Dissolved gas analysis (DGA) is a popular technique because of its reliability, sensitivity, and comprehensiveness. 
Application of the information from the DGA can be used in various ways, among them age assessment, maintenance planning, and fault diagnosis. There are numerous techniques applied in aging determination and fault diagnosis found in the literature. These are either conventional or unconventional tools. The most standardized conventional ones are the IEEE C75.104 method based on the major gases generated as given in reference [6], the three IEC gas ratios documented in [7], the Doernenburg and the Rogers gas ratios documented in [10], the CIGRE TF 15.01.01 ratios and concentrations thresholds in [11], and visual methods such as the popular Duval triangles 1-7, pentagons 1 and 2 [4,5], the recent combined pentagon in [12] and Diaa-Eldin pentagon proposed in 2015 [13]. None of the above conventional methods has yielded perfect results in fault analysis, prompting researchers to turn to unconventional techniques otherwise known as artificial intelligence (AI).

The AI methods are developed from human knowledge combined with massive field data of observed cases. They try to adopt a flexible mathematical formula coupled with natural observations-that is, they have learning capability. Typical examples are Fuzzy Logic (FL), which mimics the human reasoning to approximate the solutions to a problem [9,10]; Neural Networks $(\mathrm{NN})$, which tries to synthesize information such as the biological body neutrons [14,15]; Support Vector Machines, either a supervised or unsupervised learning algorithm for fault classification used in [2,15-17]; the Genetic Algorithms (GA), which imitate the biological gene mutations in breeding to replicate genetic information [2], and the combined flexible fuzzy logic and neural networks known as Adaptive Neuro Fuzzy Inference Systems (ANFIS) $[2,18,19]$. To date, no standard unconventional technique has been internationally agreed upon and documented, mainly because the structure that relates inputs to outputs is mainly a black box. AI tools are highly dependent on the expert knowledge and data used to build them, which is a major disadvantage in terms of standardization. However, they can be made adaptive to even recognize new features, unlike the convectional numerical tools. To date, the most standardized highly accurate conventional tools for fault diagnosis remains the Duval triangles and pentagons $[4,20,21]$.

This work carries out a detailed study evaluating the degree of healthiness $(\mathrm{DOH})$ from the Rogers and the carbon oxides gas ratios when the dissolved gases have attained their analytical detection limits or otherwise using the IEEE C57.104 normal condition one. When these ratios have been violated, meaning there is a fault, the degree of faultiness (DOF) is calculated to give the extent of fault severity. The most common ways of assessing the presence of an abnormal or normal condition in an oil-immersed equipment are by use of IEEE C57.104 four condition criteria, IEC 60,599, and Rogers gas ratios $[6,7,20]$. Based on IEEE C57.104, any equipment whose gas levels do not exceed condition one is considered to be normal provided no previous records or recent history are available, or when it has recently been repaired [6]. The key disadvantage is that the condition one gives a range of dissolved gas values to be considered as normal; this may not fit in all organizations and varies among equipment type. IEC60599 has similar proposed gas ranges that can be applied to determine normal equipment. As in the IEE C57.104 standard, it suffers from the same demerits.

Rogers gas ratios have been widely adopted as reliable parameters to distinguish normal and faulty equipment $[10,20]$. They have an advantage relative to the IEEE gas ranges, since they are ratios that have narrow ratio range limits, facilitating consistency in their application. Another advantage that is the main motivation of this research is that they can be used to calculate objectively the extent of healthiness for normal equipment or extent of faultiness for abnormal equipment.

Most researchers after applying Rogers ratios and realizing the apparatus to be healthy do not proceed to evaluate the extent of its healthiness. This work seeks to cure this gap by demonstrating that right from when the equipment is new and throughout its entire life, Rogers gas ratios can give the location of the healthiness trajectory. This trajectory moves from infinity toward the fault region as equipment ages and or enters this region when it develops a fault. Equally critical is that when these ratios show an abnormality in equipment, they can be used to quantify objectively the severity of faulting based on the extent of their violations. Numerous researchers have tried to calculate the 
severity of a fault by estimating energy released or absorbed during faulting or using the rate of gas increments and gas levels.

The authors in [22] proposed a method of determining fault severity based on energy released or absorbed during faulting from an eicosane $\left(\mathrm{C}_{20} \mathrm{H}_{42}\right)$ paraffinic oil molecule when it decomposes to generate; $\mathrm{H}_{2}, \mathrm{CH}_{4}, \mathrm{C}_{2} \mathrm{H}_{2}, \mathrm{C}_{2} \mathrm{H}_{6}, \mathrm{C}_{2} \mathrm{H}_{4}$ and cellulose disintegrate to produce $\mathrm{CO}, \mathrm{H}_{2}$, and $\mathrm{CO}_{2}$. A similar school of thought was suggested by researchers in [23], but they used the n-octane $\left(\mathrm{C}_{8} \mathrm{H}_{18}\right)$ molecule instead of eicosane. In both cases, the $\mathrm{H}_{2}$ produced from paper decomposition alongside carbon oxides was neglected. Furthermore, eicosane and n-octane molecules are assumed to not be the actual molecules that generate dissolved gases; the actual ones are unknown. So, this school of thought has inherent inaccuracies when finding the fault severity. In reference [24], it is noted that using the gas amounts with a scoring table without considering the DGA interpretation and gas rates is not sufficient. Scoring in itself is a subjective technique; thus, it will differ among organizations. Therefore, they proposed a method using gas amounts, rate, and DGA interpretation based on the Duval Pentagon Method (DPM). Although this technique is better than the former ones in [22,23], it will only work with the rate if the fault inception time and how fast the fault is developing is monitored are known. Faults occur randomly; hence, at the first instant the fault is detected, no rate information is available. In addition, the DPM is not $100 \%$ accurate. Thus, this work proposes a school of thought using DOF based on Rogers and $\mathrm{CO}_{2} / \mathrm{CO}$ gas ratios as a possible alternative. In addition, when the rate is available, it can be used to calculate how fast the DOF is changing. This will take care of the rate of faulting. So, the authors believe that the DOF and $\mathrm{DOH}$ concepts are worthy alternatives.

Furthermore, fault identification is performed using numerical and artificial intelligence techniques. Fuzzy logic is applied in determination of DOH, DOF, and fault diagnosis. Fuzzy logic combined with evidential reasoning and IEC gas ratios are applied in fault characterization. To aid the investigations, a model in MATLAB Simulink (Version 2017b from MathWorks, Natick, MA, USA) was developed for the simulation and analysis of DOH, DOF, and fault identification. To verify the results, 138 faults of a physically inspected electrical apparatus were used. These 138 faults are only the six IEC faults (PD, D1, D2, T1, T2, and T3) and not the more advanced faults of Duval Triangles 4 and 5 and Pentagon $2(\mathrm{~T} 3-\mathrm{H}, \mathrm{C}, \mathrm{O}, \mathrm{S})$. Based on the results of this work, the applicability criteria of DOH and DOF in operations and maintenance activities are suggested. In regard to fault identification results, the superiority and weaknesses of the different techniques used based on efficacy, overlapping, unresolved, and misdiagnosed cases are evident. Faults were classified into five classes based on IEC60599 standards [7,25]. This ideology stems from what fault damage features can visibly be seen and their distinctiveness from those produced by the others. These classes are:

- Partial discharges (PDs); faults that are characterized by cold plasma, which is visually seen as $\mathrm{X}$-wax formed and subsequently deposited on the solid insulation;

- Electrical discharge of low energy (EDLE); a class of stresses that appears as small arcs, which physically leave marks of tracks and tree-like structures in the cellulosic paper. Visually, they manifests as paper punctures having the shape of tree branches and solid insulation carbonizing on the surface, in addition to the appearance of carbon specks in oil. This category of faults, especially the sparking type, can also physically be recognized by the tinny carbonized punctures they make on the cellulose wrapped around the current-carrying parts;

- Electrical discharges of high energy (EDHE); these are faults caused when a major arc strikes and momentarily or permanently results into a short circuit; they may be observed visually by the high charring they produce of the cellulosic paper, the melting of metallic parts, and even at times the operation of equipment protection systems;

- Low and medium-temperature thermal faults (LMTTF); overheating stresses in liquid and/or solid insulation systems with low (below $300^{\circ} \mathrm{C}$ ) temperature visually evidenced by cellulose insulation turning into brownish and medium (above $300{ }^{\circ} \mathrm{C}$ but below $700{ }^{\circ} \mathrm{C}$ ) manifesting itself physically by turning the paper into charcoal-like material; 
- High-temperature thermal faults (HTTF); serious overheating that may occur in both liquid and solid insulation jointly or separately with temperatures of $700{ }^{\circ} \mathrm{C}$ and more, it is characterized visually by oil and cellulose forming carbon particles, changing of metal color, and even melting.

\section{Methodology}

This section outlines the logical way the research was done and is divided into four areas. Firstly, it explains the concepts of the degree of healthiness and faultiness of a device. Secondly, it includes the analysis to determine the degree of healthiness of an electrical device considered as having no fault. This will be characterized by the degree of healthiness (DOH). Thirdly, it contains the evaluation of how serious the fault is for an electrical device that is considered faulty. It will be referred to as the faultiness of the equipment, and it will be quantified by the degree of faultiness (DOF). The final subsection deals with fault diagnostics using numerical and artificial intelligence techniques. The details for each scenario are elaborated in the proceeding subsections.

\subsection{Concept of Degree of Healthiness and Faultiness of an Equipment}

The concept of degree of healthiness (DOH) and/or degree of faultiness (DOF) can be explained with the help of a diagram, as illustrated in Figure 1. This is a visual representation of the location of the trajectory characterizing the healthiness or faultiness of an equipment at any given time. Looking at the five locations shown- $\mathbf{U}, \mathbf{V}, \mathbf{W}, \mathbf{Y}$ and $\mathbf{Z}$ - the condition of a device at $\mathbf{U}, \mathbf{V}$, and $\mathbf{W}$ is healthy, with $\mathbf{U}$ being healthier than both $\mathbf{V}$ and $\mathbf{W}$, and $\mathbf{V}$ being healthier than $\mathbf{W}$. Similarly, on the side of faultiness, equipment whose fault trajectory lies at $\mathbf{Z}$ is more faulty than the one at $\mathbf{Y}$. There is a region of uncertainty around the boundary between the healthiness and faultiness areas. This may be so since the healthiness and faultiness are not crisp values but rather continuous evolving phenomenon affected by the errors in the measuring of variables used to calculate them. The condition status of equipment deemed to have suffered a more damaging fault will lie at point $\mathbf{Z}$. Such an ideology is a vital concept useful to maintenance, operations, asset managers, and engineers.

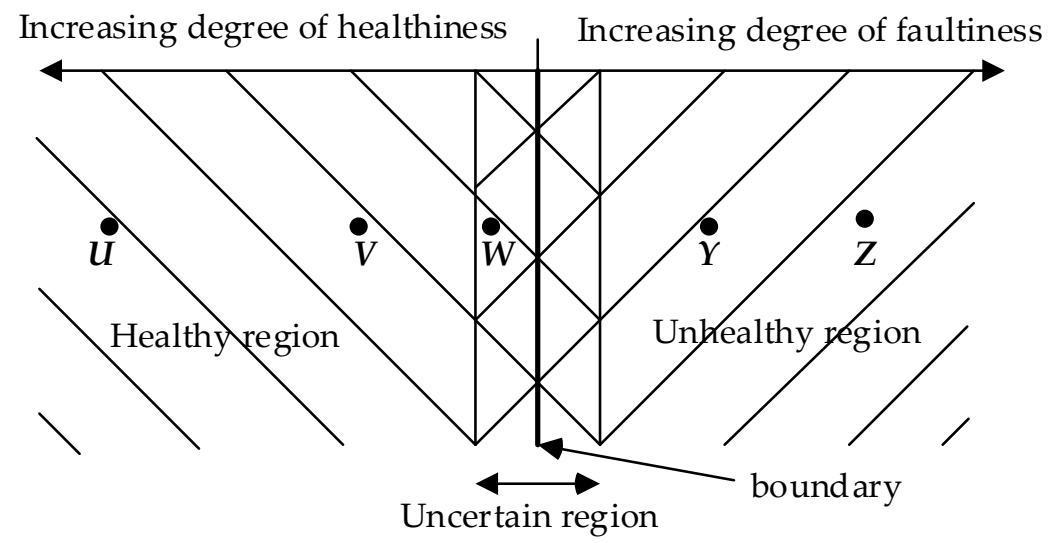

Figure 1. An illustration diagram showing the concept of degree of healthiness and faultiness.

\subsection{Determining the Degree of Healthiness of an Equipment}

There are seven extractable gases dissolved in oil for use to ascertain the health status of equipment. These are two carbon oxides; carbon monoxide $(\mathrm{CO})$ and carbon dioxide $\left(\mathrm{CO}_{2}\right)$; hydrogen $\left(\mathrm{H}_{2}\right)$, as well as four hydrocarbon gases; ethylene $\left(\mathrm{C}_{2} \mathrm{H}_{4}\right)$, methane $\left(\mathrm{CH}_{4}\right)$, acetylene $\left(\mathrm{C}_{2} \mathrm{H}_{2}\right)$, and ethane $\left(\mathrm{C}_{2} \mathrm{H}_{6}\right)$ [25-27]. All these with the exception of $\mathrm{CO}_{2}$ are combustible. A criterion using three Rogers ratios, $\mathrm{C}_{2} \mathrm{H}_{2} / \mathrm{C}_{2} \mathrm{H}_{4}<0.1,0.1<\mathrm{CH}_{4} / \mathrm{H}_{2}<1$, and $\mathrm{C}_{2} \mathrm{H}_{4} / \mathrm{C}_{2} \mathrm{H}_{6}<1$, in addition to the $3 \leq \mathrm{CO}_{2} / \mathrm{CO} \leq 10$ ratio, is widely applied to ascertain the presence of a fault(s) in an oil-immersed electrical equipment [6]. If these ratios lie within the ranges shown, then the equipment is regarded as normal. Note the authors have assumed that the $\mathrm{CO}_{2}$ and $\mathrm{CO}$ gases present were generated from chemical faulting (oil oxidation) 
or faulting (chemical or electrical or thermal) involving cellulose. This logic is based on that fact IEC has indicated that $\mathrm{CO}$ and $\mathrm{CO}_{2}$ can be formed in sealed transformers due to oil oxidation [7]. In addition, the authors in reference [28] also stated that these two carbon oxides gases can be produced from both oil and paper when oxygen is available. They also indicated that moisture can lead to the same. This might introduce an error in our DOF analysis, but DGA is not an exact science, as acknowledged under the limitations section of IEEE C57.104-2008.

The extent to which the equipment is healthy—-that is, degree of healthiness (DOH)—can be calculated from these ratios. However, for them to be dependable, the combustibles must be at least 10 times the corresponding logical minimum detection limit given in Table $1[7,27]$. This is to ensure that they are reliable. If this is not the case, the alternative method applied to determine the $\mathrm{DOH}$ is by use of the condition one gas limits in IEEE C57.104-2008 being taken as normal [6]. Based on this, per unit $\mathrm{DOH}_{1}$ is evaluated by Equation (1). The ratios or gas magnitude alone may not wholly give a reliable DOH. The rate of increase of these gases as given in Table 1 can bridge this shortcoming. Thus, a second $\mathrm{DOH}_{2}$ can be calculated based on this rate of combustible gas increases per day when such data are available. This is given by Equation (2) based on IEEE C57.104 condition 1 for a TDCG rate of less than $10 \mathrm{ppm} /$ day and TDCG level below or equal to $720 \mathrm{ppm} \mathrm{[6]}$. $\mathrm{DOH}_{1}$ can be combined with $\mathrm{DOH}_{2}$ to get the aggregate DOH as given by Equation (3).

$$
\begin{aligned}
\mathrm{DOH}_{1} & =1-\frac{\text { total dissoved combustible gases }}{720} \\
\mathrm{DOH}_{2} & =1-\frac{\text { Daily incremental rate of TDCG }}{10} \\
& \text { Aggregate DOH }=\frac{\mathrm{DOH}_{1}+\mathrm{DOH}_{2}}{2}
\end{aligned}
$$

where TDCG is the sum of Total Dissolved Combustible Gases.

Table 1. Dissolved gas analysis (DGA) analytical detection limit and normal incremental rate per day $[7,27]$.

\begin{tabular}{cccccccc}
\hline Gas Type & $\mathrm{H}_{2}$ & $\mathrm{CH}_{4}$ & $\mathrm{C}_{2} \mathrm{H}_{6}$ & $\mathrm{C}_{2} \mathrm{H}_{4}$ & $\mathrm{C}_{2} \mathrm{H}_{2}$ & $\mathrm{CO}$ & $\mathrm{CO}_{2}$ \\
\hline Logical detection limit (ppm) [24] & 5 & 1 & 1 & 1 & 1 & 25 & 25 \\
\hline $\begin{array}{c}\text { Normal incremental rate } \\
\text { (ppm/day) }{ }^{*}[7]\end{array}$ & $<0.36$ & $<0.33$ & $<0.25$ & $<0.4$ & $<0.01$ & $<2.9$ & $<27.4$ \\
\hline
\end{tabular}

* Based on IEC60599-2015 upper limit of ranges of 90\% typical rates of gas increase observed in power transformers of all types in $\mu \mathrm{L} / \mathrm{L} /$ year converted into per day.

To evaluate the relative $\mathrm{DOH}_{1}$ given reliable gas ratios, all the ratios are mapped to suitable fuzzy linguistic curves. Every ratio is fully characterized by three to five such curves, namely, Healthier $(\mathrm{H})$, More Healthier $(\mathrm{MH})$, and Highly Healthier $(\mathrm{HH})$, and the output is the same. The pictorial representation of this concept is shown in Figure 2. The $\mathrm{DOH}_{1}$ can also be evaluated numerically given reliable gas ratios using the following concept elaborated with Equations (4)-(8). Consider the ratio $R_{1}$, the degree of healthiness $\left(\mathrm{DOH}_{1}\right)$ assessed from this ratio will be as given by Equation (4).

$$
\mathrm{DOH}_{1, \mathrm{R}_{1}}\left(\mathrm{R}_{1}=\frac{\mathrm{C}_{2} \mathrm{H}_{2}}{\mathrm{C}_{2} \mathrm{H}_{4}}<0.1\right)=\left\{\begin{array}{cc}
\frac{0.1-\mathrm{R}_{1}}{\mathrm{R}_{1}} & \mathrm{R}_{1}<0.1 \\
0 & \mathrm{R}_{1} \geq 0.1
\end{array}\right\}
$$




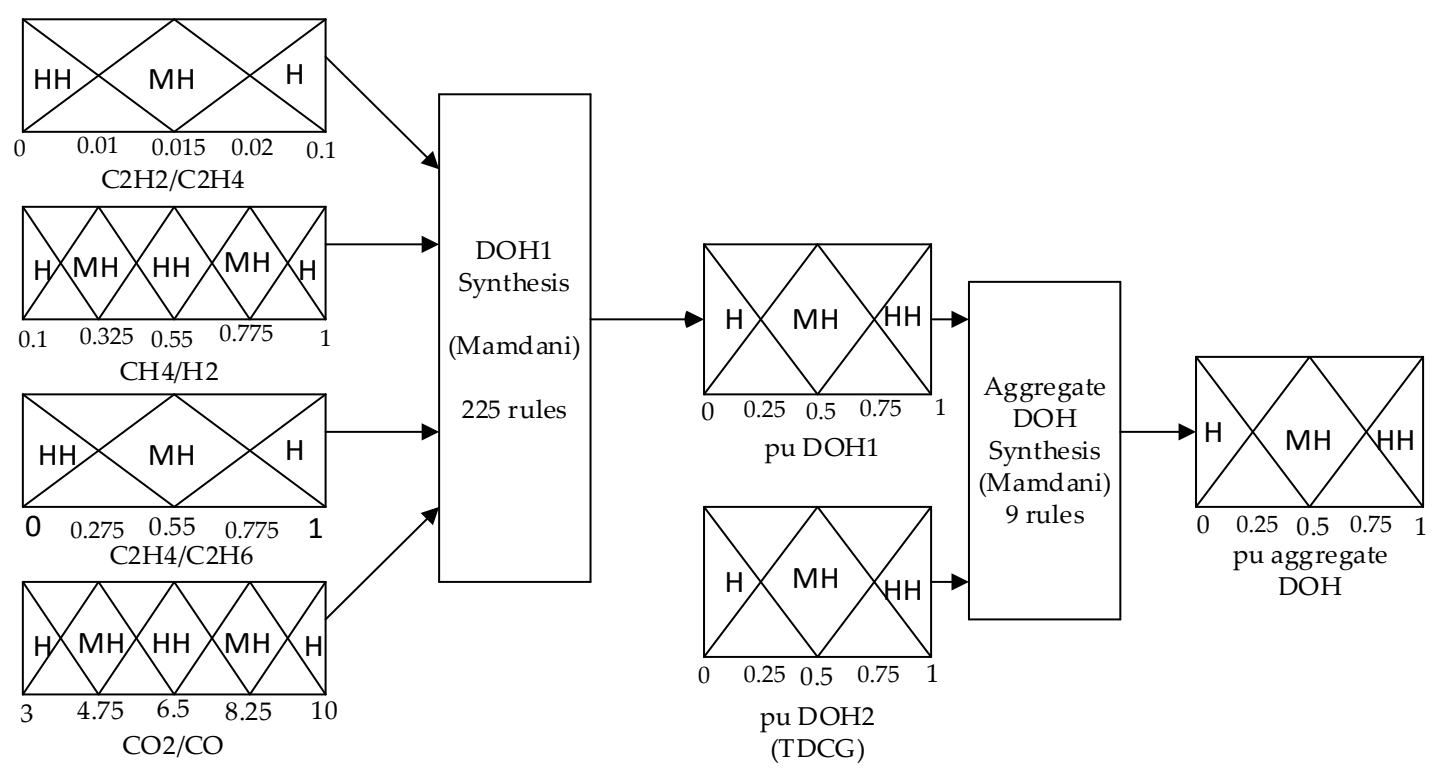

Figure 2. An illustration diagram showing how degree of healthiness (DOH) is evaluated by fuzzy logic.

For example, a fault-free equipment with $\mathrm{R}_{1}=0$ meaning $\mathrm{C}_{2} \mathrm{H}_{2}=0$, its $\mathrm{DOH}_{1}$, due to $\mathrm{R}_{1}$ is infinity, signifying that the equipment is Highly Healthier $(\mathrm{HH})$ based on fuzzy logic, as shown in Figure 2. Interpreting this using Figure 1, it means based on $R_{1}$, the healthiness is at the furthest point on the left side of the boundary separating the healthiness and faultiness of equipment status.

For $\mathrm{R}_{2}, \mathrm{DOH}_{1}$ will be as computed by Equation (5). The healthiness of equipment with $\mathrm{R}_{2}=0.55$ will have infinity $\mathrm{DOH}_{1}$, which is represented by Highly Healthier $(\mathrm{HH})$ in fuzzy logic.

$$
\mathrm{DOH}_{1, \mathrm{R}_{2}}\left(0.1<\mathrm{R}_{2}=\frac{\mathrm{CH}_{4}}{\mathrm{H}_{2}}<1\right)=\left\{\begin{array}{cc}
\frac{0.55}{\mathrm{R}_{2}-0.55} & 0.55 \leq \mathrm{R}_{2}<1 \\
\frac{0.55}{0.55-\mathrm{R}_{2}} & 0.1<\mathrm{R}_{2} \leq 0.55 \\
0 & 0.1 \geq \mathrm{R}_{2} \geq 1
\end{array}\right\}
$$

$\mathrm{DOH}_{1}$ as determined from $\mathrm{R}_{3}$ will be given by Equation (6). For example, if $\mathrm{R}_{3}=1$, it means that the equipment status is exactly on the boundary between healthiness and faultiness, as viewed in Figure 1, or $\mathrm{DOH}_{1}=0$ as evaluated from $\mathrm{R}_{3}$. Zero is the reference/boundary point for both healthiness and faultiness. As viewed in Figure 2, this will be regarded as Healthier $(\mathrm{H})$.

$$
\mathrm{DOH}_{1, \mathrm{R}_{3}}\left(\mathrm{R}_{3}=\frac{\mathrm{C}_{2} \mathrm{H}_{4}}{\mathrm{C}_{2} \mathrm{H}_{6}}<1\right)=\left\{\begin{array}{cc}
\frac{1-\mathrm{R}_{3}}{\mathrm{R}_{3}} & \mathrm{R}_{3}<1 \\
0 & \mathrm{R}_{3} \geq 1
\end{array}\right\}
$$

Now, when the carbon oxides ratio $\mathrm{R}_{4}$ is used to assess $\mathrm{DOH}_{1}$, Equation (7) is applied. An equipment with $\mathrm{R}_{4}=6.5$ will have the best healthy status; $\mathrm{DOH}_{1}$ will be infinity or Highly Healthier $(\mathrm{HH})$ based on fuzzy reasoning. An equipment having $\mathrm{R}_{4}=9$ will have its healthiness being Healthier $(\mathrm{H})$ from Figure 2 or 2.6 steps of measure on the left from the boundary separating healthiness from faultiness in Figure 1. Lastly, the overall $\mathrm{DOH}_{1}$ evaluation from the four ratios is as given by Equation (8).

$$
\begin{gathered}
\mathrm{DOH}_{1, \mathrm{R}_{4}}\left(3<\mathrm{R}_{4}=\frac{\mathrm{CO}_{2}}{\mathrm{CO}}<10\right)=\left\{\begin{array}{cc}
\frac{6.5}{\mathrm{R}_{4}-6.5} & 6.5 \leq \mathrm{R}_{4}<10 \\
\frac{6.5}{6.5-\mathrm{R}_{4}} & 3<\mathrm{R}_{4} \leq 6.5 \\
0 & 3 \geq \mathrm{R}_{4} \geq 10
\end{array}\right\} \\
\mathrm{DOH}_{1}=\frac{\mathrm{DOH}_{1, \mathrm{R}_{1}}+\mathrm{DOH}_{1, \mathrm{R}_{2}}+\mathrm{DOH}_{1, \mathrm{R}_{3}}+\mathrm{DOH}_{1, \mathrm{R}_{4}}}{4}
\end{gathered}
$$

Then, this $\mathrm{DOH}_{1}$ can be fused with $\mathrm{DOH}_{2}$ to give the overall degree of healthiness where applicable. 
The authors chose to apply the triangular fuzzy membership curves in light of their experience to represent this information. In order to include the rate of increment of TDCG as given by Equation (2) in the $\mathrm{DOH}$ overall assessment, this rate was also transformed into fuzzy triangular membership functions and combined with $\mathrm{DOH}_{1}$ from the Rogers ratios and $\mathrm{CO}_{2} / \mathrm{CO}$ assessment, as shown in Figure 2. This figure visually illustrates how to synthesize the $\mathrm{DOH}_{1}, \mathrm{DOH}_{2}$, and the overall $\mathrm{DOH}$ from fuzzy IF-THEN rules based on the fuzzy logic technique. Typical fuzzy rules for synthesizing $\mathrm{DOH}$ based on Rogers and $\mathrm{CO}_{2} / \mathrm{CO}$ ratios are:

1. $\mathrm{IF} \mathrm{R}_{1}$ is $\mathrm{HAND} \mathrm{R}_{2}$ is $\mathrm{HAND} \mathrm{R}_{3}$ is $\mathrm{H} \mathrm{AND} \mathrm{R}_{4}$ is $\mathrm{H}$ THEN $\mathrm{DOH}_{1}$ is $\mathrm{H}$

2. IF $R_{1}$ is $M H A N D R_{2}$ is MH AND $R_{3}$ is $H_{A N D} R_{4}$ is $M H$ THEN DOH ${ }_{1}$ is $M H$

3. IF $R_{1}$ is $H H A N D R_{2}$ is MH AND $R_{3}$ is $H_{A N D} R_{4}$ is MH THEN DOH ${ }_{1}$ is MH

4. $\mathrm{IF}_{1}$ is $\mathrm{HH}$ AND $\mathrm{R}_{2}$ is $\mathrm{MH} \mathrm{AND} \mathrm{R}_{3}$ is $\mathrm{HH} \mathrm{AND} \mathrm{R}_{4}$ is $\mathrm{HH}$ THEN $\mathrm{DOH}_{1}$ is $\mathrm{HH}$

5. IF $R_{1}$ is MH AND $R_{2}$ is MH AND $R_{3}$ is $H H A N D R_{4}$ is MH THEN DOH ${ }_{1}$ is MH

6. IF $\mathrm{DOH}_{1}$ is $\mathrm{H}$ AND $\mathrm{DOH}_{2}$ is $\mathrm{H}$ THEN DOH is $\mathrm{H}$

7. IF $\mathrm{DOH}_{1}$ is $\mathrm{HH}$ AND $\mathrm{DOH}_{2}$ is $\mathrm{H}$ THEN DOH is $\mathrm{MH}$

8. IF $\mathrm{DOH}_{1}$ is $\mathrm{MH}$ AND $\mathrm{DOH}_{2}$ is MH THEN DOH is $\mathrm{MH}$

If there is no rate of change of TDCG to synthesize $\mathrm{DOH}_{2}$, then $\mathrm{DOH}_{1}$ in Figure 2 becomes the aggregate $\mathrm{DOH}$ for the device under consideration.

\subsection{Evaluating the Degree of Faultiness of an Equipment}

The presence of a fault is assumed whenever the Rogers ratio test for healthiness fails, provided the gas ratios are reliable. The degree of faultiness (DOF) can be calculated from the extent to which the Rogers and $\mathrm{CO}_{2} / \mathrm{CO}$ ratios for fault-free equipment have been violated. Accordingly, the following criterion is assumed to hold; if the violation lies between 1 and 5 times, the case is considered Faulty (F), between 5 and 10 times, it is considered More Faulty (MF), and above 10 times, it is considered Extremely Faulty (EF). Figure 3 shows a physical representation of this philosophy. The mathematical knowledge behind Figure 3 is as explained by Equations (9)-(13). The DOF due to $R_{1}$ violation is calculated by Equation (9). As an illustration, a faulty equipment with $R_{1}=10$ will have a DOF due $R_{1}$ of 99 , meaning the status of faultiness is 99 steps or times from the boundary between the healthiness and faultiness on the far right of Figure 1. Based on Figure 3, a 99 steps/times degree of ratio violation is characterized by Extremely Faulty (EF).

$$
\operatorname{DOF}_{\mathrm{R}_{1}}\left(\mathrm{R}_{1}=\frac{\mathrm{C}_{2} \mathrm{H}_{2}}{\mathrm{C}_{2} \mathrm{H}_{4}}<0.1\right)=\left\{\begin{array}{cc}
\frac{\mathrm{R}_{1}-0.1}{0.1} & \mathrm{R}_{1}>0.1 \\
0 & \mathrm{R}_{1} \leq 0.1
\end{array}\right\}
$$

When the $R_{2}$ ratio is violated, the extent of violation can be quantified numerically by Equation (10).

$$
\operatorname{DOF}_{R_{2}}\left(0.1<\mathrm{R}_{2}=\frac{\mathrm{CH}_{4}}{\mathrm{H}_{2}}<1\right)=\left\{\begin{array}{cc}
\frac{\mathrm{R}_{2}-1}{1} & \mathrm{R}_{2}>1 \\
\frac{0.1-\mathrm{R}_{2}}{\mathrm{R}_{2}} & \mathrm{R}_{2}<0.1 \\
0 & 0.1 \leq \mathrm{R}_{2} \leq 1
\end{array}\right\}
$$

To illustrate via an example, consider two faulty pieces of equipment: one where $R_{2}=8$ and the other where $R_{2}=0.0125$. These extent of $R_{2}$ ratio violation or degree of faultiness for these two pieces of equipment will be DOF $=7$. This shows that both apparatus possesses More Faulty (MF) faulting, as given in Figure 3. Using Figure 1, the DOF of 7 steps/times will lie 7 steps of measure from the boundary separating the healthiness from faultiness on the right. Applying the $R_{3}$ ratio violation to determine its contribution to DOF is as given by Equation (11). A faulty apparatus with $R_{3}=2$ will 
have a DOF based on this ratio of 1, meaning its faultiness level is Faulty (F), as shown in Figure 3, and lies just 1 step of measure from the healthiness/faultiness boundary to the right in Figure 1.

$$
\operatorname{DOF}_{\mathrm{R}_{3}}\left(\mathrm{R}_{3}=\frac{\mathrm{C}_{2} \mathrm{H}_{4}}{\mathrm{C}_{2} \mathrm{H}_{6}}<1\right)=\left\{\begin{array}{cc}
\frac{\mathrm{R}_{3}-1}{1} & \mathrm{R}_{3}>1 \\
0 & \mathrm{R}_{3} \leq 1
\end{array}\right\}
$$

The last ratio $R_{4}$ when violated and used gives the DOF as expressed by Equation (12). A faulty apparatus with $R_{4}=21$ will have a DOF evaluated on this ratio as 1.1, meaning this equipment has suffered a Faulty $(F)$ fault, whereas another piece of equipment with $R_{4}=0.36$ will have a DOF of 7.333 , which is a More Faulty (MF) level of faulting.

$$
\operatorname{DOF}_{R_{4}}\left(3<R_{4}=\frac{C O_{2}}{C O}<10\right)=\left\{\begin{array}{cc}
\frac{\mathrm{R}_{4}-10}{10} & \mathrm{R}_{4}>10 \\
\frac{3-\mathrm{R}_{4}}{\mathrm{R}_{4}} & \mathrm{R}_{4}<3 \\
0 & 3 \leq \mathrm{R}_{4} \leq 10
\end{array}\right\}
$$

Finally, the fusion of all four ratios during faulting gives the aggregate degree of faultiness suffered by the equipment. This mathematically is synthesized by Equation (13).

$$
\mathrm{DOF}=\frac{\mathrm{DOF}_{\mathrm{R}_{1}}+\mathrm{DOF}_{\mathrm{R}_{2}}+\mathrm{DOF}_{\mathrm{R}_{3}}+\mathrm{DOF}_{\mathrm{R}_{4}}}{4}
$$
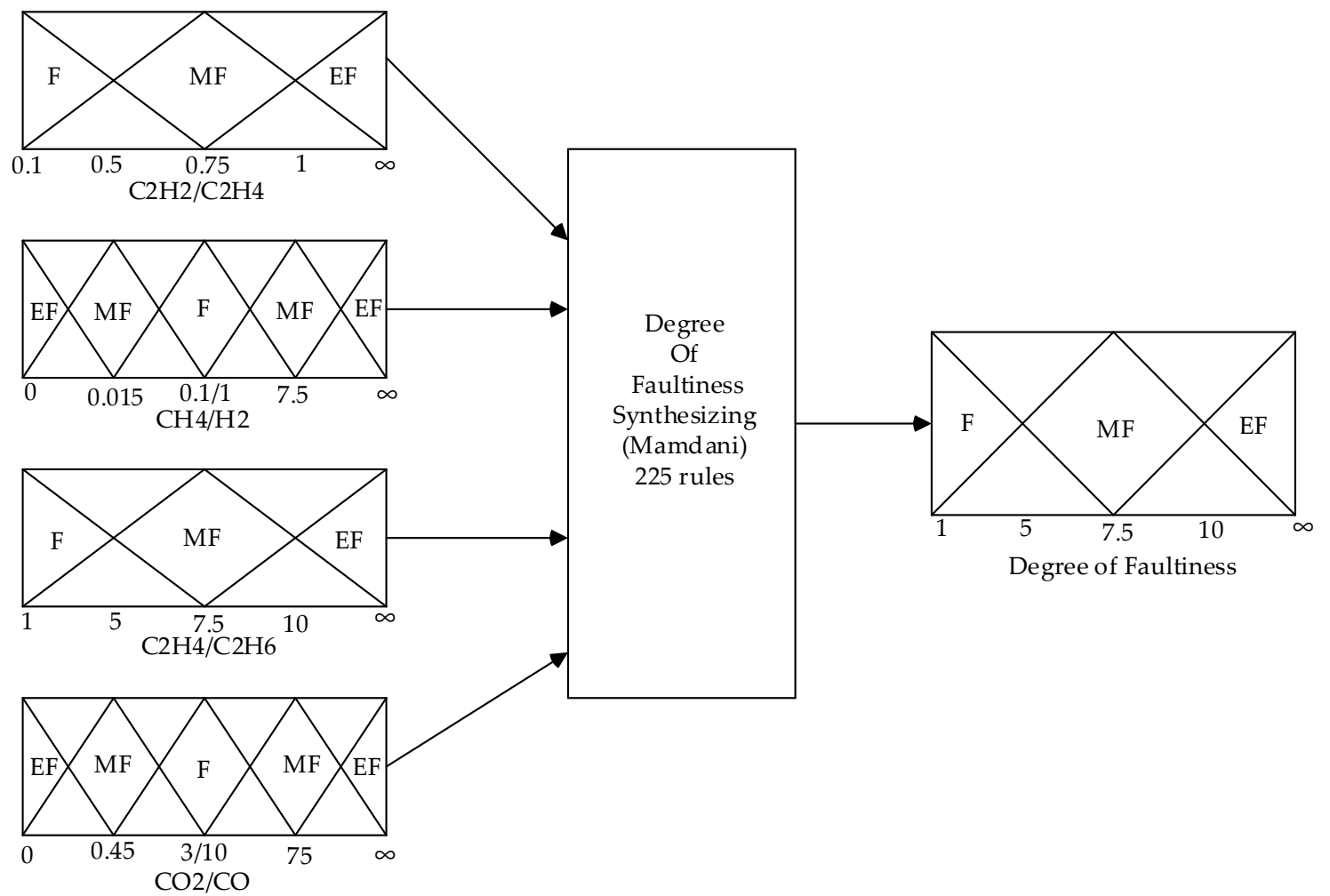

Figure 3. Schematic diagram on how to synthesize degree of faultiness (DOF) based on fuzzy logic.

A transformer or any other device diagnosed as faulty may be classified as having a faulty, more faulty, or extremely faulty fault depending on its calculated DOF. Then, this parameter determined from the degree of violation of the Rogers ratio and $\mathrm{CO}_{2} / \mathrm{CO}$ test for a healthy device can be used as follows. When the classification is faulty, the device can still remain in operation with continuous monitoring, no overloading, and it can possibly operate at a reduced load and require scheduled maintenance soon. For a more faulty fault, the device can operate, but the operator should consider 
urgent shutdown to prevent further damage. Lastly, an extremely faulty fault plan requires an immediate shutdown to avoid catastrophic imminent failure such as an explosion. The results of 138 fault cases documented in references $[3,12,25]$ were used to elaborate the applicability of this ideological concept. Other concepts used by researchers to estimate the degree of fault severity includes that given in [22,23], which estimates the faulty severity based on the energy of fault formation and that given by Prasojo et al. in [24], which uses the gas level, gas rate, and fault type based on the Duval pentagon technique interpretation.

\subsection{Application of Numerical Technique in Fault Diagnosis_IEC Gas Ratios}

The IEC gas ratio technique for fault mapping is a known and highly adopted fault identification numerical method. It entails the use of three gas ratios, as shown in Table 2 [7]. Based on this standard technique, faults are categorized into six types: partial discharges (PDs), electrical discharge of low energy (EDLE), electrical discharge of high energy (EDHE), low-temperature $\left(<300^{\circ} \mathrm{C}\right)$ thermal faults (LTTF), medium-temperature $\left(>300^{\circ} \mathrm{C}\right.$ but $\left.<700{ }^{\circ} \mathrm{C}\right)$ thermal faults (MTTF), and high-temperature $\left(>700^{\circ} \mathrm{C}\right.$ ) thermal faults (HTTF). However, these were reduced to five according to faults that can be visually verified and have clear distinctiveness. Consequently, the LTTF and MTTF were merged to form the low and medium-temperature thermal faults (LMTTF) $[7,25]$.

Table 2. IEC60599 DGA fault diagnostic criteria [7].

\begin{tabular}{ccccccc}
\hline Fault Class & PDs & EDLE & EDHE & LTTF & MTTF & HTTF \\
\hline$\frac{\mathrm{C}_{2} \mathrm{H}_{2}}{\mathrm{C}_{2} \mathrm{H}_{4}}$ & NS & $>1$ & $0.6-2.5$ & NS & $<0.1$ & $<0.2$ \\
\hline$\frac{\mathrm{CH}_{4}}{\mathrm{H}_{2}}$ & $<0.1,<0.2^{1}$ & $0.1-0.5$ & $0.1-1.0$ & $>1 / \mathrm{NS}^{2}$ & $>1$ & $>1$ \\
\hline$\frac{\mathrm{C}_{2} \mathrm{H}_{4}}{\mathrm{C}_{2} \mathrm{H}_{6}}$ & $<0.2$ & $>1$ & $>2$ & $<1$ & $1-4$ & $>4$ \\
\hline
\end{tabular}

${ }^{1}$ for measurement transformers, NS = considered unnecessary irrespective of the magnitude. $\mathrm{NS}^{2}=$ ignored in some countries.

\subsection{Fault Identification Based on Artificial Intelligence Techniques}

Faults in oil-immersed equipment will always involve oil even if it occurs in cellulose insulation. This is because the solid cellulose is covered by oil. To distinguish whether the fault occurred in oil only or in the cellulose in oil insulation, the presence of the carbon oxides $\left(\mathrm{CO}\right.$ and $\left.\mathrm{CO}_{2}\right)$ is used. A fault in oil will not produce significant quantities of the two carbon oxides gases only. Their presence and their ratio $\left(\mathrm{CO}_{2} / \mathrm{CO}<3\right.$ or $\left.\mathrm{CO}_{2} / \mathrm{CO}>10\right)$ characterizes the occurrence of a fault in cellulose. Three of the seven dissolved gases given in Section 2.2 show a high ability to characterize a wide range of faults; these are ethylene, methane, and acetylene. Each when divided by their sum yields per-unit quantity as illustrated by Equations (14)-(16) [4,7]. The fuzzy characteristic functions used in Figures 4-8 correspond to the different regions characterizing faults on the Duval Triangle 1 and Pentagon 1 for the six IEC faults $[4,7,20]$.

$$
\begin{aligned}
\mathrm{CH}_{4}(\mathrm{pu}) & =\frac{\mathrm{CH}_{4}}{\mathrm{CH}_{4}+\mathrm{C}_{2} \mathrm{H}_{2}+\mathrm{C}_{2} \mathrm{H}_{4}} \\
\mathrm{C}_{2} \mathrm{H}_{2}(\mathrm{pu}) & =\frac{\mathrm{C}_{2} \mathrm{H}_{2}}{\mathrm{CH}_{4}+\mathrm{C}_{2} \mathrm{H}_{2}+\mathrm{C}_{2} \mathrm{H}_{4}} \\
\mathrm{C}_{2} \mathrm{H}_{4}(\mathrm{pu}) & =\frac{\mathrm{C}_{2} \mathrm{H}_{4}}{\mathrm{CH}_{4}+\mathrm{C}_{2} \mathrm{H}_{2}+\mathrm{C}_{2} \mathrm{H}_{4}}
\end{aligned}
$$

From the authors' experience, the normalized gas quantities in Equations (14)-(16) can be described by certain fuzzy curves, which give the possibility of occurrence of one or more of the five categories of 
faults. Mostly, these fuzzy curves take the form of a trapezoidal kind of characteristic, which generally has the form of Equation (17) [8,10],

$$
\mathrm{f}(\mathrm{x}, \mathrm{r}, \mathrm{s}, \mathrm{t}, \mathrm{u})=\max \left[\min \left\{\frac{\mathrm{x}-\mathrm{r}}{\mathrm{s}-\mathrm{r}}, 1, \frac{\mathrm{u}-\mathrm{x}}{\mathrm{u}-\mathrm{t}}\right\}, 0\right], \mathrm{r}<\mathrm{t}<\mathrm{s}<\mathrm{u}
$$

where $\mathrm{r}, \mathrm{s}, \mathrm{t}$, and $\mathrm{u}$ are the $\mathrm{x}$-coordinates of the corners of the trapezium, while the $\mathrm{y}$-coordinates vary from 0 to 1 and give the degree of membership.

The resulting level of membership from these curves gives the probability value assignments (PVAs) of specific faults. PVAs show the extent to which each gas supports of any of the five faults. The fuzzy curves showing the way they characterize faults for each of the three sources of evidence-i.e., from ethylene, acetylene, and methane gases-are illustrated by Figures $4-8$. The gases will be labeled $\mathrm{A}, \mathrm{B}$, and $\mathrm{C}$ in the per-unit system values for methane, acetylene, and ethylene, respectively, in their mathematical expressions for these curves. Likewise, the Greek symbols $\chi_{i}(A), \Psi_{i}(B)$, and $\gamma_{i}(C)$ consecutively will stand for the fuzzy degree of membership for the fault $i=1,2,5$ under consideration in $\mathrm{A}, \mathrm{B}$, and $\mathrm{C}$.

From A, B, and $C$, the characterization of the partial discharges $(i=1)$ fault represented by the curves in Figure 4 can mathematically be given by Equations (18)-(20).

$$
\begin{gathered}
\chi_{\mathrm{PDs}}(\mathrm{A})=\left[\begin{array}{cc}
0 & \mathrm{CH}_{4} \leq 0.97 \\
100 \mathrm{~A}-97 & 0.97<\mathrm{CH}_{4}<0.98 \\
1 & 0.98 \leq \mathrm{CH}_{4} \leq 1
\end{array}\right] \\
\Psi_{\mathrm{PDs}}(\mathrm{B})=\left[\begin{array}{cc}
0 & 0.03 \leq \mathrm{C}_{2} \mathrm{H}_{2} \\
-100 \mathrm{~B}+3 & 0.02<\mathrm{C}_{2} \mathrm{H}_{2}<0.03 \\
1 & 0 \leq \mathrm{C}_{2} \mathrm{H}_{2} \leq 0.02
\end{array}\right] \\
\gamma_{\mathrm{PDs}}(\mathrm{C})=\left[\begin{array}{cc}
0 & 0.03 \leq \mathrm{C}_{2} \mathrm{H}_{4} \\
-100 \mathrm{C}+3 & 0.02 \leq \mathrm{C}_{2} \mathrm{H}_{4}<0.03 \\
1 & 0 \leq \mathrm{C}_{2} \mathrm{H}_{4}<0.02
\end{array}\right]
\end{gathered}
$$

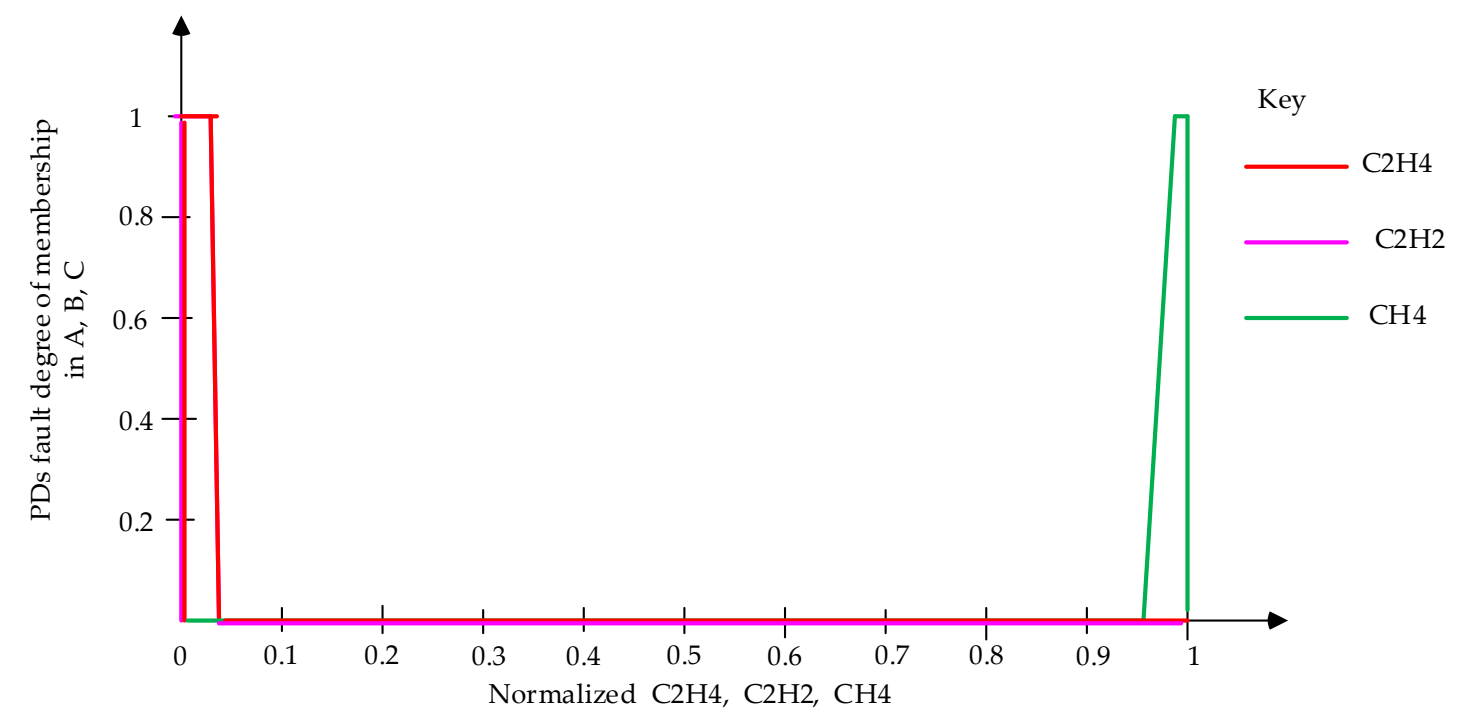

Figure 4. Fuzzy membership functions characterizing the presence of partial discharges (PDs). 
Figure 5 illustrates how the low and medium-temperature thermal faults (LMTTF, $i=2)$ can be represented by fuzzy membership curves. The corresponding numerical equations of these curves quantifying the degrees of membership are as given by Equations (21)-(23).

$$
\begin{gathered}
\chi_{\text {LMTTF }}(\mathrm{A})=\left[\begin{array}{cc}
0 & 0.99 \leq \mathrm{CH}_{4} \text { or } \mathrm{CH}_{4}<0.45 \\
100 \mathrm{~A}-45 & 0.45 \leq \mathrm{CH}_{4}<0.46 \\
-100 \mathrm{~A}+99 & 0.98<\mathrm{CH}_{4}<0.99 \\
1 & 0.46 \leq \mathrm{CH}_{4} \leq 0.98
\end{array}\right] \\
\Psi_{\text {LMTTF }}(\mathrm{B})=\left[\begin{array}{cc}
0 & 0.05 \leq \mathrm{C}_{2} \mathrm{H}_{2} \\
-100 \mathrm{~B}+5 & 0.04<\mathrm{C}_{2} \mathrm{H}_{2}<0.05 \\
1 & 0 \leq \mathrm{C}_{2} \mathrm{H}_{2} \leq 0.04
\end{array}\right] \\
\gamma_{\mathrm{LMTTF}}(\mathrm{C})=\left[\begin{array}{cc}
0 & 0.51 \leq \mathrm{C}_{2} \mathrm{H}_{4} \\
-100 \mathrm{C}+51 & 0.5<\mathrm{C}_{2} \mathrm{H}_{4}<0.51 \\
1 & 0 \leq \mathrm{C}_{2} \mathrm{H}_{4} \leq 0.5
\end{array}\right]
\end{gathered}
$$

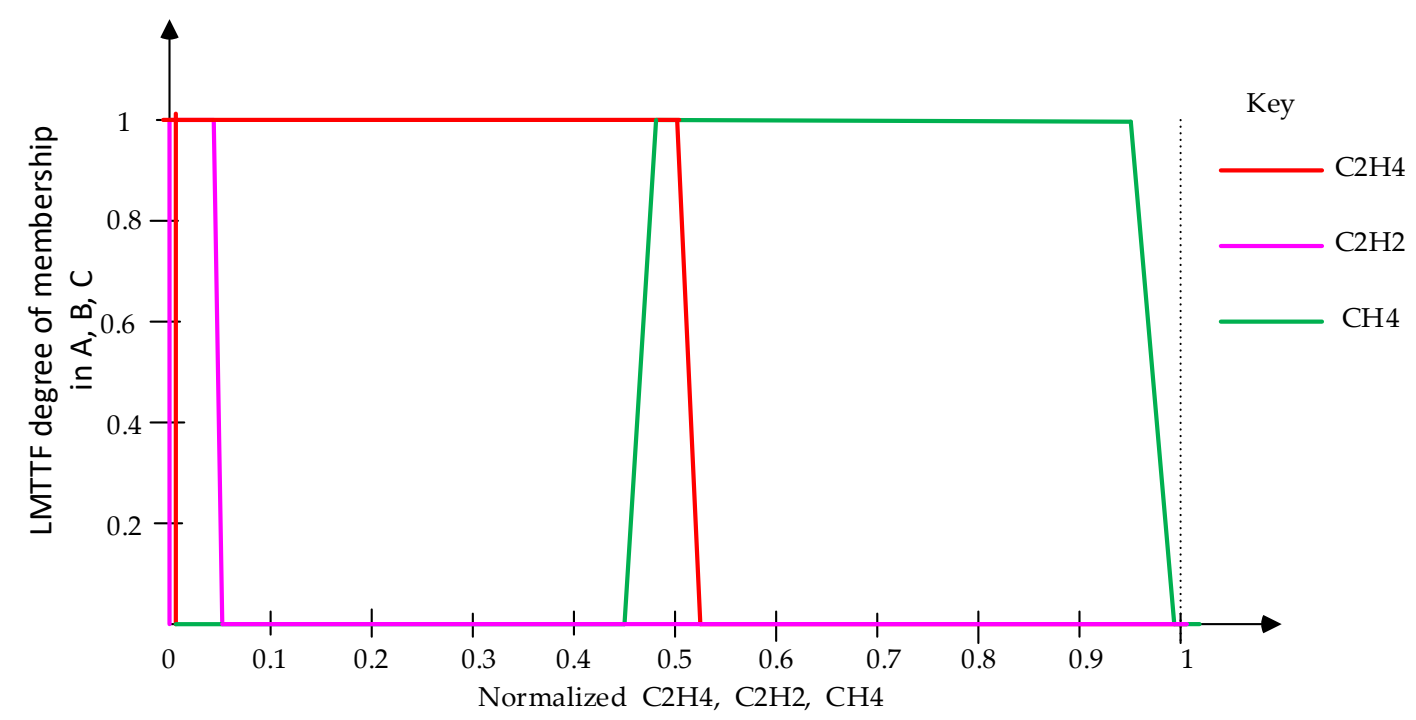

Figure 5. Fuzzy membership functions for analyzing the presence of low and medium-temperature thermal faults (LMTTF).

Equally, based on the $A, B$, and $C$ quantities, the fuzzy membership function for high-temperature thermal faults (HTTF, $i=3$ ) are as shown in Figure 6 and expressed mathematically by Equations (24)-(26).

$$
\begin{gathered}
\chi_{\mathrm{HTTF}}(\mathrm{A})=\left[\begin{array}{cc}
0 & 0.51 \leq \mathrm{CH}_{4} \\
-100 \mathrm{~A}+51 & 0.50<\mathrm{CH}_{4}<0.51 \\
1 & 0 \leq \mathrm{CH}_{4} \leq 0.50
\end{array}\right] \\
\Psi_{\mathrm{HTTF}}(\mathrm{B})=\left[\begin{array}{ll}
0 & 0.16 \leq \mathrm{C}_{2} \mathrm{H}_{2} \\
-100 \mathrm{~B}+16 & 0.15<\mathrm{C}_{2} \mathrm{H}_{2}<0.16 \\
1 & 0 \leq \mathrm{C}_{2} \mathrm{H}_{2} \leq 0.15
\end{array}\right] \\
\gamma_{\mathrm{HTTF}}(\mathrm{C})=\left[\begin{array}{ll}
0 & \mathrm{C}_{2} \mathrm{H}_{4}<0.49 \\
100 \mathrm{C}-49 & 0.49 \leq \mathrm{C}_{2} \mathrm{H}_{4}<0.5 \\
1 & 0.5 \leq \mathrm{C}_{2} \mathrm{H}_{4} \leq 1
\end{array}\right]
\end{gathered}
$$




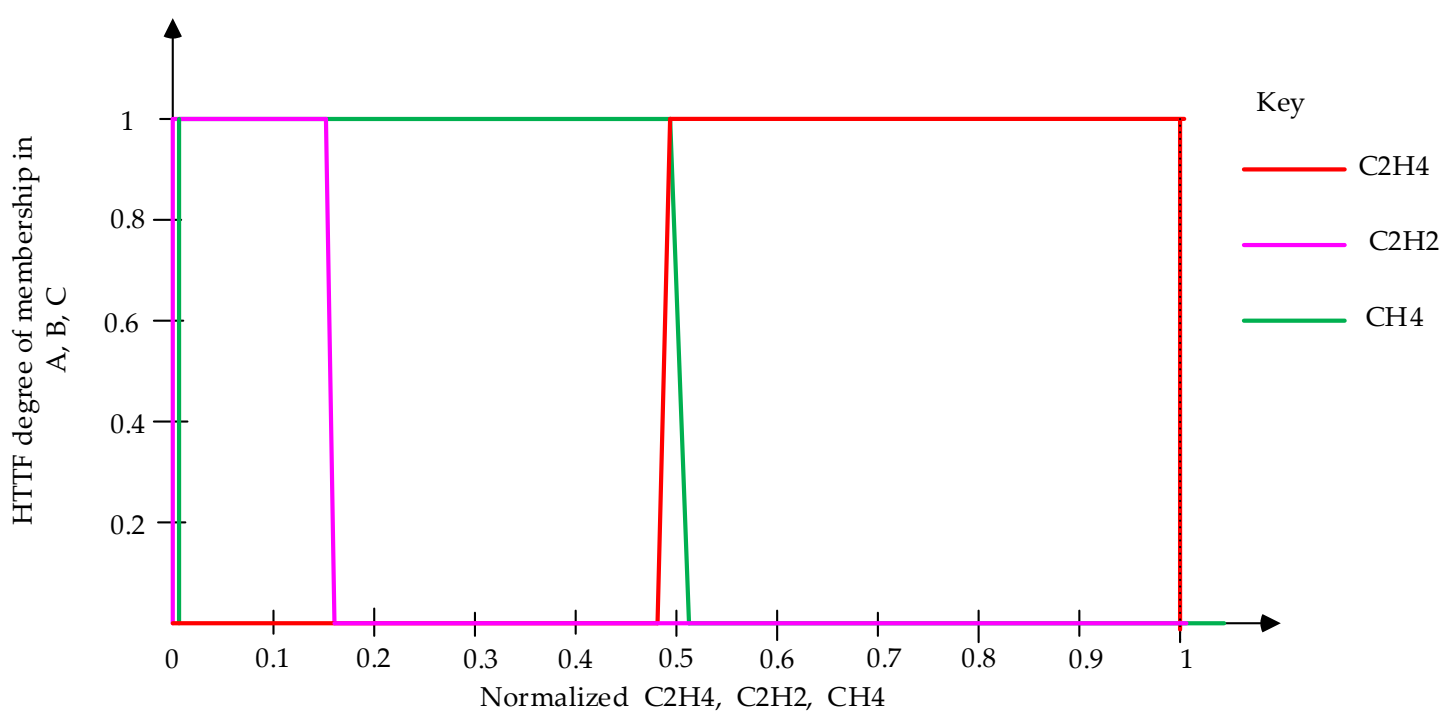

Figure 6. Fuzzy characteristic curves for evaluating an occurrence of high-temperature thermal faults (HTTF).

The electrical discharges of low energy (EDLE, $i=4$ ) faults are characterized by the curves shown in Figure 7 and numerically by Equations (27)-(29).

$$
\begin{gathered}
\chi_{\mathrm{EDLE}}(\mathrm{A})=\left[\begin{array}{ll}
0 & 0.88 \leq \mathrm{CH}_{4} \\
-100 \mathrm{~A}+88 & 0.87 \leq \mathrm{CH}_{4}<0.88 \\
1 & 0 \leq \mathrm{CH}_{4}<0.87
\end{array}\right] \\
\Psi_{\mathrm{EDLE}}(\mathrm{B})=\left[\begin{array}{ll}
0 & \mathrm{C}_{2} \mathrm{H}_{2}<0.12 \\
100 \mathrm{~B}-12 & 0.12 \leq \mathrm{C}_{2} \mathrm{H}_{2}<0.13 \\
1 & 0.13 \leq \mathrm{C}_{2} \mathrm{H}_{2} \leq 1
\end{array}\right] \\
\gamma_{\mathrm{EDLE}}(\mathrm{C})=\left[\begin{array}{ll}
0 & 0.24 \leq \mathrm{C}_{2} \mathrm{H}_{4} \\
-100 \mathrm{C}+24 & 0.23<\mathrm{C}_{2} \mathrm{H}_{4}<0.24 \\
1 & 0 \leq \mathrm{C}_{2} \mathrm{H}_{4} \leq 0.23
\end{array}\right]
\end{gathered}
$$

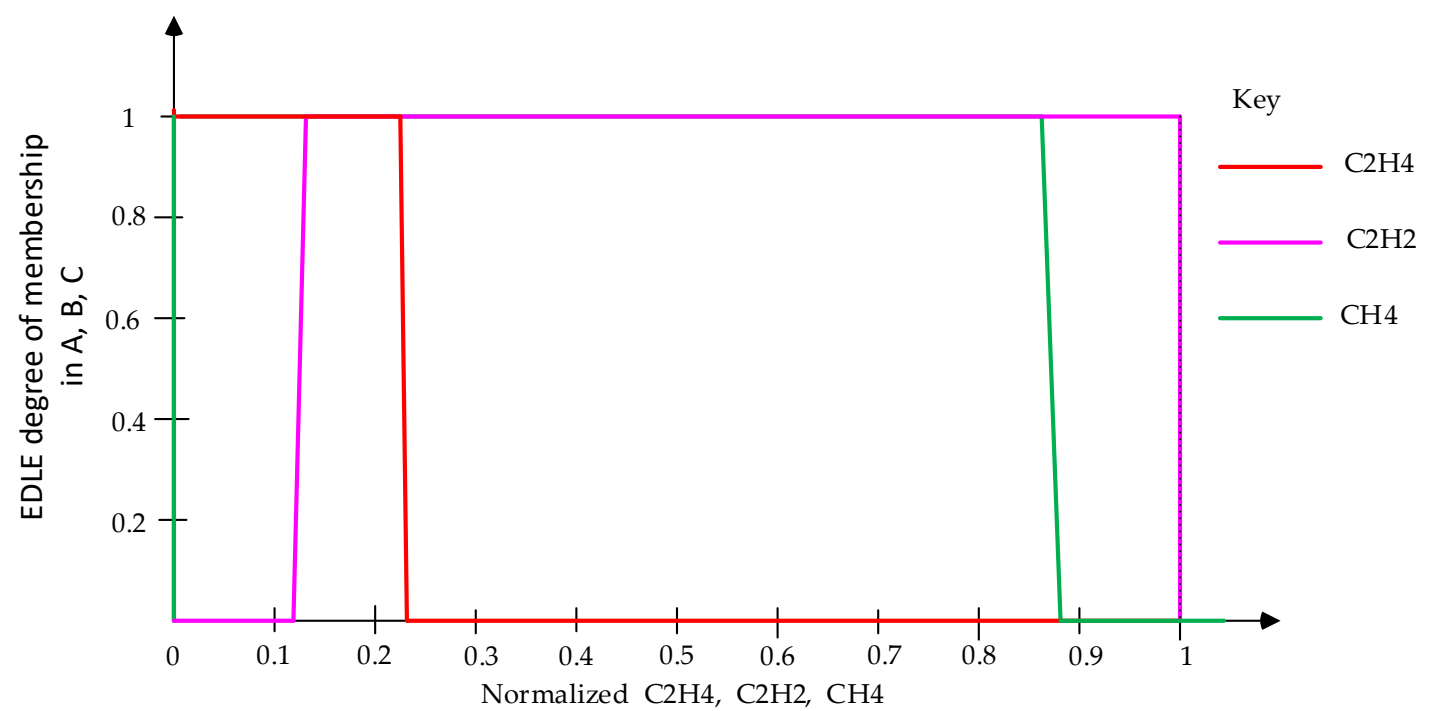

Figure 7. Fuzzy mapping curves for synthesizing electrical discharges of low energy (EDLE) faults. 
Likewise, the electrical discharge of high-energy (EDHE, $i=5)$ faults when viewed pictorially using the fuzzy mapping functions appears as illustrated in Figure 8 and represented by Equations (30)-(32).

$$
\begin{gathered}
\chi_{\mathrm{EDHE}}(\mathrm{A})=\left[\begin{array}{ll}
0 & 0.65 \leq \mathrm{CH}_{4} \\
-100 \mathrm{~A}+65 & 0.64 \leq \mathrm{CH}_{4}<0.65 \\
1 & 0 \leq \mathrm{CH}_{4}<0.64
\end{array}\right] \\
\Psi_{\mathrm{EDHE}}(\mathrm{B})=\left[\begin{array}{ll}
0 & 0.78 \leq \mathrm{C}_{2} \mathrm{H}_{2} \text { or } 0.12>\mathrm{C}_{2} \mathrm{H}_{2} \\
100 \mathrm{~B}-12 & 0.12 \leq \mathrm{C}_{2} \mathrm{H}_{2}<0.13 \\
-100 \mathrm{~B}+78 & 0.77 \leq \mathrm{C}_{2} \mathrm{H}_{2}<0.78 \\
1 & 0.13 \leq \mathrm{C}_{2} \mathrm{H}_{2}<0.77
\end{array}\right] \\
\gamma_{\mathrm{EDHE}}(\mathrm{C})=\left[\begin{array}{ll}
0 & \mathrm{C}_{2} \mathrm{H}_{4}<0.225 \text { or } 0.71<\mathrm{C}_{2} \mathrm{H}_{4} \\
100 \mathrm{C}-22.5 & 0.225 \leq \mathrm{C}_{2} \mathrm{H}_{4}<0.235 \\
-100 \mathrm{C}+71 & 0.70<\mathrm{C}_{2} \mathrm{H}_{4} \leq 0.71 \\
1 & 0.235 \leq \mathrm{C}_{2} \mathrm{H}_{4} \leq 0.70
\end{array}\right]
\end{gathered}
$$

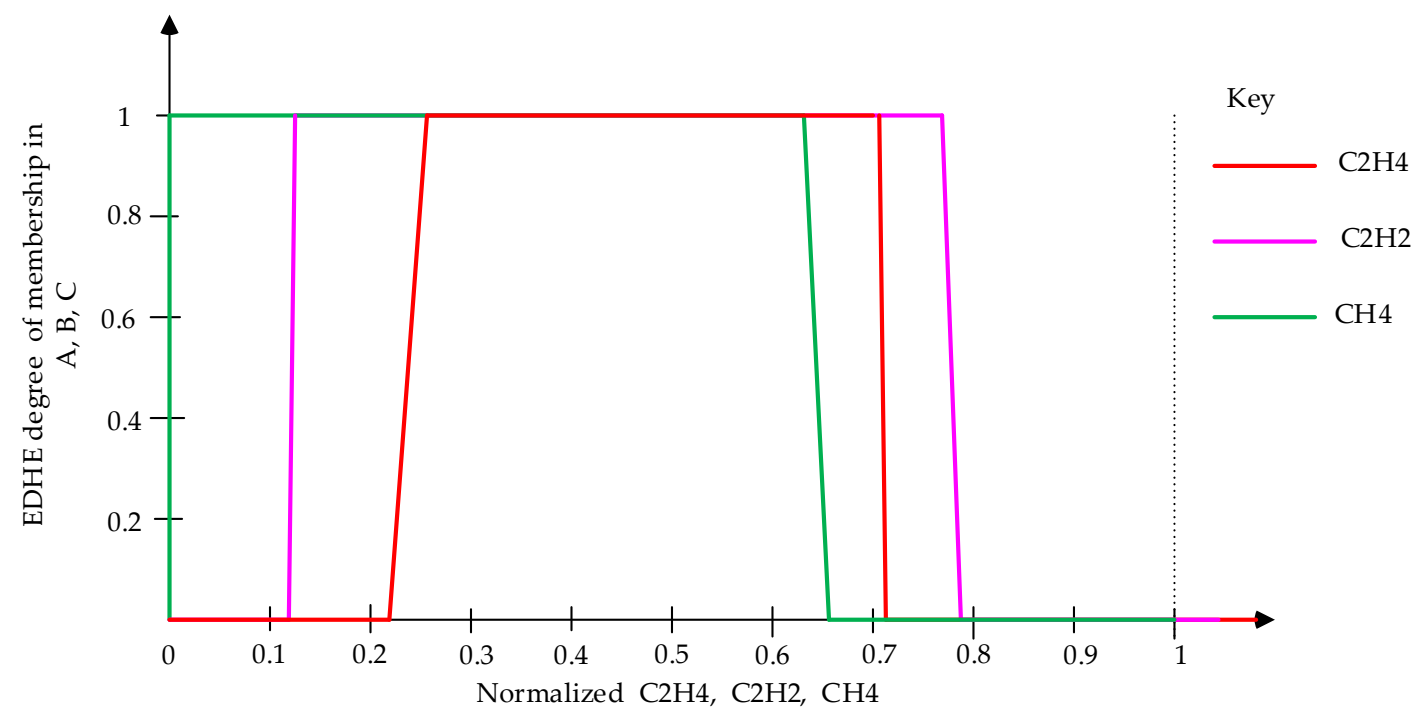

Figure 8. Characteristic curves for performing the presence of high-energy (EDHE) faults testing.

From the fault characteristic curves in Figures 4-8, to diagnose a fault using fuzzy logic, 243 IF-THEN firing rules are required. However, imposing the condition that $A+B+C=1$, only 75 rules are necessary to completely synthesize all the five categories of faults. The rules take the general form of:

IF $\chi_{i}(A)$ is $i_{1,2,5} \operatorname{AND} \Psi_{i}(B)$ is $i_{1,2,5}$ AND $\gamma_{i}(C)$ is $i_{1,2,5}$ THEN the fault is $i_{1,2,5}$.

These faults, including the case where there is NO fault condition, in addition to mixed faults, are represented by the output characteristic trapezoidal functions shown in Figure 9. The mathematical expressions for these outputs' degree of membership $(\mu)$ are as given by Equations (33)-(39). These curves transform back the fuzzy continuous outputs to crisp values. Then, 138 faults of physically inspected and verified equipment were used to test the effectiveness of this method and compare it with the IEC three-gas ratio method and fuzzy-evidential reasoning techniques.

As an example, a faulty power transformer had the following DGA sample readings: carbon monoxide 290 ppm, carbon dioxide 1500 ppm, ethane 1400 ppm, ethylene 17,700 ppm, acetylene $750 \mathrm{ppm}$, methane 10,500 ppm and hydrogen $6709 \mathrm{ppm}$; the values of $\mathrm{A}, \mathrm{B}$, and $\mathrm{C}$ are $0.36,0.03$, and 0.61 , respectively. The strongest firing rule will be: 
$\operatorname{IF} \chi_{i}(A=0.36)$ is $1(\mathrm{ONE}) i=3 \mathrm{AND} \Psi_{i}(B=0.03)$ is $1(\mathrm{ONE}) i=3 \mathrm{AND} \gamma_{i}(C=0.61)$ is $1(\mathrm{ONE})$ $i=3$ THEN the fault is HTTF. This was a high-temperature thermal fault caused by circulating currents between yoke clamps and connecting bolts, as reported in [25].

$$
\begin{gathered}
\text { Nofault } \mu_{\mathrm{NF}}=\left\{\begin{array}{cc}
1 & 0 \leq \mathrm{X} \leq 0.04 \\
0 & 0.04 \leq \mathrm{X} \leq 0.12
\end{array}\right\} \\
\mu_{\mathrm{PDs}}=\left\{\begin{array}{cc}
12.5 \mathrm{X}-0.5 & 0.04 \leq \mathrm{X} \leq 0.12 \\
1 & 0.12 \leq \mathrm{X} \leq 0.2 \\
-12.5 \mathrm{X}+3.5 & 0.2 \leq \mathrm{X} \leq 0.28
\end{array}\right\} \\
\mu_{\mathrm{LMTTF}}=\left\{\begin{array}{cc}
12.5 \mathrm{X}-2.5 & 0.2 \leq \mathrm{X} \leq 0.28 \\
1 & 0.28 \leq \mathrm{X} \leq 0.36 \\
-12.5 \mathrm{X}+5.5 & 0.36 \leq \mathrm{X} \leq 0.44
\end{array}\right\} \\
\mu_{\mathrm{HTTF}}=\left\{\begin{array}{cc}
12.5 \mathrm{X}-4.5 & 0.36 \leq \mathrm{X} \leq 0.44 \\
1 & 0.44 \leq \mathrm{X} \leq 0.52 \\
-12.5 \mathrm{X}+7.5 & 0.52 \leq \mathrm{X} \leq 0.6
\end{array}\right\} \\
\mu_{\mathrm{EDLE}}=\left\{\begin{array}{cc}
12.5 \mathrm{X}-6.5 & 0.52 \leq \mathrm{X} \leq 0.6 \\
1 & 0.6 \leq \mathrm{X} \leq 0.68 \\
-12.5 \mathrm{X}+9.5 & 0.68 \leq \mathrm{X} \leq 0.76
\end{array}\right\} \\
\mu_{\mathrm{EDHE}}=\left\{\begin{array}{cc}
12.5 \mathrm{X}-8.5 & 0.68 \leq \mathrm{X} \leq 0.76 \\
1 & 0.76 \leq \mathrm{X} \leq 0.84 \\
-12.5 \mathrm{X}+11.5 & 0.84 \leq \mathrm{X} \leq 0.92
\end{array}\right\} \\
\text { mixed fault } \mu_{\mathrm{MF}}=\left\{\begin{array}{cc}
12.5 \mathrm{X}-10.5 & 0.84 \leq \mathrm{X} \leq 0.92 \\
1 & \mathrm{X} \geq 0.92
\end{array}\right\}
\end{gathered}
$$

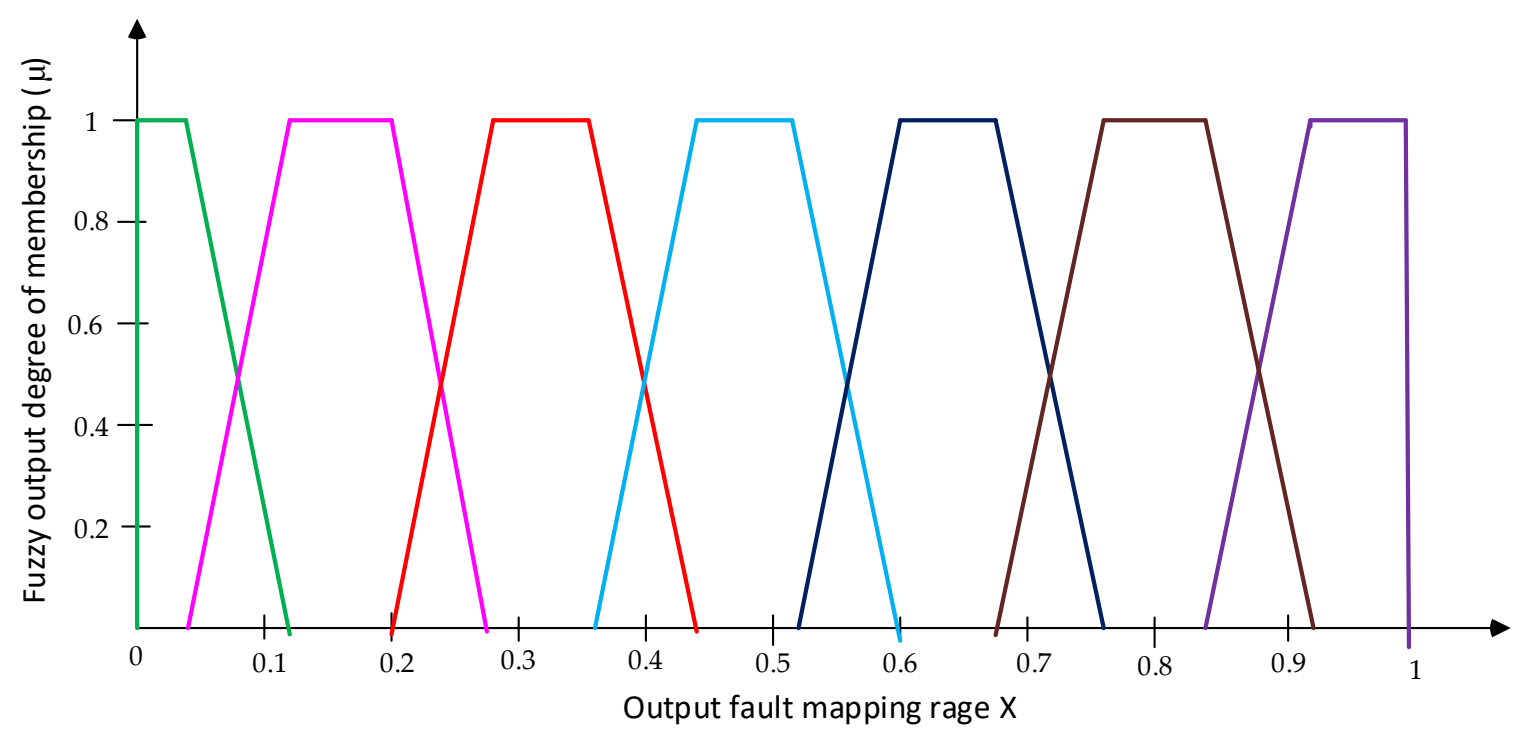

Figure 9. Functions used to defuzzify the degree of membership to crisp output.

Using FL can be tedious, and errors can creep in during rules formulation; instead, the fault identification can be completed from the fuzzified inputs degree of memberships using evidential reasoning (ER). ER is firm mathematical theory started by Dempster and advanced by Shaffer [29-34]. It has superior ability to combine evidence from various data sources to actionable information. The Dempster-Shaffer formula given by Equation (40) is applied to combine the evidence from the 
PVAs given by Equations (18)-(32). Two evidential sources are fused at a time, as illustrated in Table 3. The degree of memberships from Figures 4-8-that is, $\chi_{i}(A), \Psi_{i}(B)$, and $\gamma_{i}(C)$-represents the evidence to be fused. Once combined, the fault type with the greatest PVA signifies the identified fault.

$$
\begin{gathered}
E(\alpha)=\sum_{\chi_{i}(A) \cap \Psi_{i}(B) \cap \gamma_{i}(C)=\alpha} \frac{\chi_{i}(A) \otimes \Psi_{i}(B) \otimes \gamma_{i}(C)}{1-\psi} \\
\psi=\sum_{\chi_{i}(A) \cap \Psi_{i}(B) \cap \gamma_{i}(C)=\Phi} \chi_{i}(A) \otimes \Psi_{i}(B) \otimes \gamma_{i}(C)
\end{gathered}
$$

where $\psi$ signifies the level of disagreement amongst $\chi_{i}(A), \Psi_{i}(B)$, and $\gamma_{i}(C)$, and $\Phi$ is their combination where they yield a null set, subject to the condition given by Equation (42).

$$
\sum \frac{x_{i=1,2, \ldots, 5}(A)}{\sum_{i=1}^{5} x_{i}(A)}=\sum \frac{\Psi_{i=1,2, \ldots, 5}(B)}{\sum_{i=1}^{5} \Psi_{i}(B)}=\sum \frac{\gamma_{i=1,2, \ldots, 5}(C)}{\sum_{i=1}^{5} \gamma_{i}(C)}=1
$$

\begin{tabular}{|c|c|c|c|c|c|c|}
\hline \multirow{2}{*}{$\begin{array}{c}\text { Sources of Evidence } \\
\chi_{i}(A) \text { and } \Psi_{i}(B)\end{array}$} & \multicolumn{6}{|c|}{$\chi_{i}(A)$} \\
\hline & PVAs & $\chi_{P D s}$ & $\chi_{\text {LMTTF }}$ & $\chi_{\text {HTTF }}$ & $\chi_{E D L E}$ & $\chi_{E D H E}$ \\
\hline \multirow{5}{*}{$\Psi_{i}(B)$} & $\Psi_{P D s}$ & $\alpha(1,1)$ & $\Phi(1,2)$ & $\Phi(1,3)$ & $\Phi(1,4)$ & $\Phi(1,5)$ \\
\hline & $\Psi_{L M T T F}$ & $\Phi(2,1)$ & $\alpha(2,2)$ & $\Phi(2,3)$ & $\Phi(2,4)$ & $\Phi(2,5)$ \\
\hline & $\Psi_{H T T F}$ & $\Phi(3,1)$ & $\Phi(3,2)$ & $\alpha(3,3)$ & $\Phi(3,4)$ & $\Phi(3,5)$ \\
\hline & $\Psi_{E D L E}$ & $\Phi(4,1)$ & $\Phi(4,2)$ & $\Phi(4,3)$ & $\alpha(4,4)$ & $\Phi(4,5)$ \\
\hline & $\Psi_{E D H E}$ & $\Phi(5,1)$ & $\Phi(5,2)$ & $\Phi(5,3)$ & $\Phi(5,4)$ & $\alpha(5,5)$ \\
\hline
\end{tabular}

Table 3. Table illustrating evidence fusion from two sources $\chi_{i}(A)$ and $\Psi_{i}(B)$.

The PVAs are organized in a row matrix form as given by Equations (43) to (45). The outcome fault emerging with the highest PVA represents the diagnosed fault.

$$
\begin{gathered}
\chi(\mathrm{A})=\left[\begin{array}{lllll}
\chi_{\mathrm{PDs}} & \chi_{\mathrm{LMTTF}} & \chi_{\mathrm{HTTF}} & \chi_{\mathrm{EDLE}} & \chi_{\mathrm{EDHE}}
\end{array}\right] \\
\Psi(\mathrm{B})=\left[\begin{array}{lllll}
\Psi_{\mathrm{PD}} & \Psi_{\mathrm{LMTTF}} & \Psi_{\mathrm{HTTF}} & \Psi_{\mathrm{EDLE}} & \Psi_{\mathrm{EDHE}}
\end{array}\right] \\
\gamma(\mathrm{C})=\left[\begin{array}{lllll}
\gamma_{\mathrm{PDs}} & \gamma_{\mathrm{LMTTF}} & \gamma_{\mathrm{HTTF}} & \gamma_{\mathrm{EDLE}} & \gamma_{\mathrm{EDHE}}
\end{array}\right]
\end{gathered}
$$

As an illustration, consider a fault with the following DGA results: hydrogen 1900 ppm, methane 530 ppm, acetylene 434 ppm, ethylene 383 ppm, ethane 35 ppm, carbon monoxide 1890 ppm, and carbon dioxide $7570 \mathrm{ppm}$. Using Equations (14)-(16), the per-unit consecutive quantities of methane, acetylene, and ethylene are $0.1026,0.0023$, and 0.8951 . Transforming them to PVAs, we have:

$$
\begin{aligned}
\chi(A) & =\left[\begin{array}{lllll}
0 & 0 & 1 & 1 & 1
\end{array}\right] \\
\Psi(B) & =\left[\begin{array}{lllll}
0 & 0 & 0 & 1 & 1
\end{array}\right] \\
\gamma(\mathrm{C}) & =\left[\begin{array}{lllll}
0 & 1 & 0 & 0 & 1
\end{array}\right] .
\end{aligned}
$$

The PVAs given by Equations (46)-(48) when subjected to the condition in Equation (42) before evidence combination yield:

$$
\chi(\mathrm{A})_{\mathrm{N}}=\left[\begin{array}{lllll}
0 & 0 & \frac{1}{3} & \frac{1}{3} & \frac{1}{3}
\end{array}\right]
$$




$$
\begin{aligned}
& \Psi(\mathrm{B})_{\mathrm{N}}=\left[\begin{array}{lllll}
0 & 0 & 0 & 0.5 & 0.5
\end{array}\right] \\
& \gamma(\mathrm{C})_{\mathrm{N}}=\left[\begin{array}{lllll}
0 & 0.5 & 0 & 0 & 0.5
\end{array}\right] .
\end{aligned}
$$

Applying Equation (40), the combined evidence in favor of the electrical discharge of a high-energy fault has the greatest support at $100 \%$. Thus, this is the fault that was diagnosed, and it was reported as arcing in a reactor winding in reference [25].

\section{Results}

\subsection{Degree of Healthiness}

An algorithm for carrying out the evaluation of $\mathrm{DOH}, \mathrm{DOF}$, and fault identification was developed in MATLAB Simulink. The algorithm flowchart is as shown in Figure 10. The DOH results for 10 representative transformers whose DGA field test results showed that they are healthy are as given in Table 4. This table shows that the $\mathrm{DOH}$ calculated from $\mathrm{DOH}_{1}$ or $\mathrm{DOH}_{2}$ alone may be highly skewed by a few combustible gases being high. Examples are $\mathrm{DOH}_{1}$ for Transformer 6 due to $\mathrm{CO}$ and Transformer 8 due to $\mathrm{H}_{2}$ and $\mathrm{CO}$ gases. This may not be reliable, but when this information is combined with $\mathrm{DOH}_{2}$, the resultant $\mathrm{DOH}$ changes significantly from low (from a low of $2.92 \%$ to an average of $41.96 \%$ for Transformer 8 ) to an average value, which may be more reliable. However, judicious decision and engineering expertise is required when analyzing, interpreting, and using DGA, since it is not an exact science.

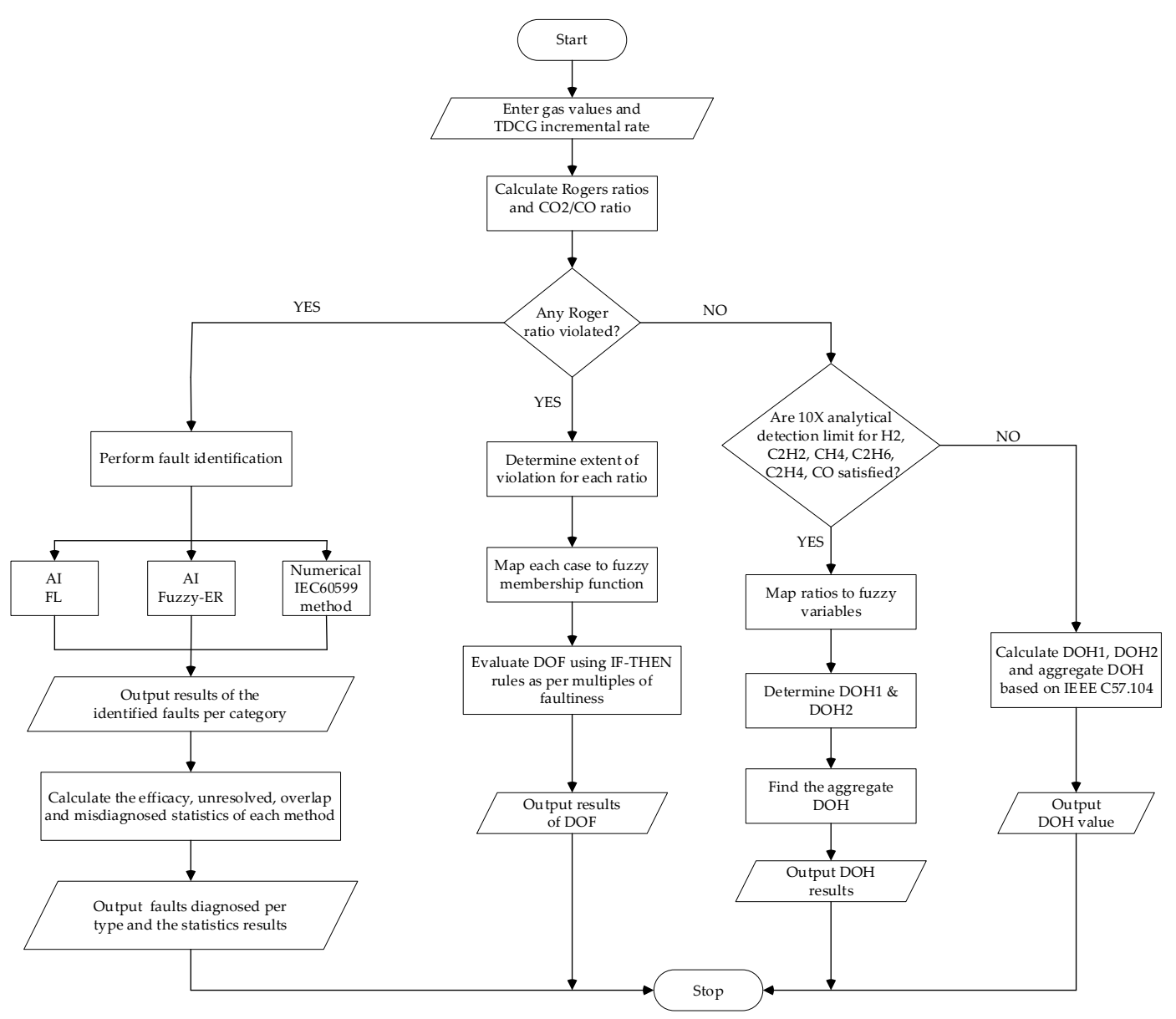

Figure 10. Flowchart for the algorithm used in MATLAB Simulink degree of healthiness (DOH), DOF, and fault diagnosis evaluation. 
Table 4. Typical transformers with degree of healthiness (DOH) calculated. TDCG: Total Dissolved Combustible Gases.

\begin{tabular}{|c|c|c|c|c|c|c|c|c|c|c|c|}
\hline \multirow{2}{*}{ 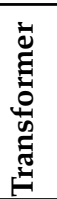 } & \multicolumn{8}{|c|}{ Measured Dissolved Gases (ppm) } & \multirow{2}{*}{$\begin{array}{l}\vec{Z} \\
0 \\
0 \\
\circ \\
\circ\end{array}$} & \multirow{2}{*}{$\begin{array}{l}\mathfrak{N} \\
0 \\
0 \\
0 \\
0^{\circ}\end{array}$} & \multirow{2}{*}{ 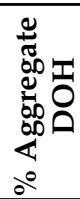 } \\
\hline & $\mathbf{H}_{2}$ & $\mathrm{CH}_{4}$ & $\mathrm{C}_{2} \mathrm{H}_{2}$ & $\mathrm{C}_{2} \mathrm{H}_{4}$ & $\mathrm{C}_{2} \mathrm{H}_{6}$ & $\mathrm{CO}$ & $\mathrm{CO}_{2}$ & $\begin{array}{c}\text { TDCG Rate } \\
\text { ppm/day }\end{array}$ & & & \\
\hline 1 & 5 & 2 & 0 & 2 & 10 & 159 & 1503 & 0.5 & 75.28 & 95 & 85.14 \\
\hline 2 & 208 & 26 & 1 & 15 & 31 & 176 & 1226 & 1.3 & 36.53 & 87 & 61.77 \\
\hline 3 & 10 & 3 & 0 & 8 & 24 & 110 & 1054 & 0.4 & 78.47 & 96 & 87.24 \\
\hline 4 & 8 & 5 & 0 & 6 & 50 & 231 & 2028 & 0.8 & 58.33 & 92 & 75.17 \\
\hline 5 & 104 & 28 & 1 & 16 & 17 & 175 & 1375 & 0.9 & 52.64 & 91 & 71.82 \\
\hline 6 & 15 & 5 & 0 & 7 & 10 & 582 & 2687 & 1.7 & 14.03 & 83 & 48.52 \\
\hline 7 & 34 & 27 & 2 & 131 & 160 & 162 & 1447 & 1.4 & 28.33 & 86 & 57.17 \\
\hline 8 & 217 & 60 & 0 & 3 & 15 & 404 & 2962 & 1.9 & 2.92 & 81 & 41.96 \\
\hline 9 & 4 & 1 & 0 & 2 & 21 & 167 & 985 & 0.5 & 72.92 & 95 & 83,96 \\
\hline 10 & 5 & 1 & 0 & 1 & 10 & 389 & 1969 & 1.2 & 43.61 & 88 & 65.81 \\
\hline
\end{tabular}

\subsection{Degree of Faultiness}

The DOF was evaluated based on fuzzy linguistic parameters Faulty $(\mathrm{F})$ if it lies between 1 and 5 times, More Faulty (MF) if it lies between 5 and 10 times, and above 10 times, it is Extremely Faulty (EF). Typical firing rules are:

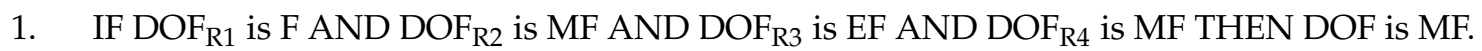

2. IF DOF $F_{R 1}$ is EF AND DOF $\mathrm{R}_{2}$ is EF AND DOF $\mathrm{R}_{\mathrm{R}}$ is $E F \mathrm{AND}^{\mathrm{DO}} \mathrm{DF}_{\mathrm{R} 4}$ is MF THEN DOF is EF.

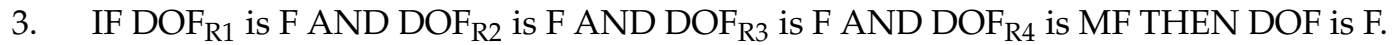

4. $\mathrm{IF} \mathrm{DOF}_{\mathrm{R} 1}$ is MF AND DOF $\mathrm{R}_{2}$ is MF AND $\mathrm{DOF}_{\mathrm{R} 3}$ is EF AND DOF $\mathrm{R}_{4}$ is MF THEN DOF is MF.

5. $\mathrm{IF} \mathrm{DOF}_{\mathrm{R} 1}$ is $\mathrm{F}$ AND $\mathrm{DOF}_{\mathrm{R} 2}$ is $\mathrm{F}$ AND $\mathrm{DOF}_{\mathrm{R} 3}$ is $\mathrm{F} \mathrm{AND}_{\mathrm{DOF}} \mathrm{D}_{\mathrm{R}}$ is $\mathrm{F}$ THEN DOF is $\mathrm{F}$.

The results of this exercise for the 138 faulted devices analyzed are as shown in Figure 11a-e. These figures illustrate that DOF happens with different levels of magnitude, even for the same kind of faults. Visually and statistically, LMTTF faults occur with the lowest DOF mean. Table 5 gives the DOF mean $(\bar{X})$, standard deviations (SD), and range (R) for each class of faults as calculated by Equations (52)-(54) respectively [35],

$$
\begin{gathered}
\bar{X}=\frac{1}{N} \sum_{i=1}^{N} x_{i} \\
S D=\sqrt{\frac{1}{N-1} \sum_{i=1}^{N}\left(x_{i}-\bar{X}\right)^{2}} \\
\mathrm{R}=\mathrm{DOF}_{\max }-\mathrm{DOF}_{\min }
\end{gathered}
$$

where $\mathrm{N}$ is the total faulty equipment per given fault type, and $\mathrm{x}_{\mathrm{i}}$ is the individual case DOF. From the mean statistic DOF based on Rogers and $\mathrm{CO}_{2} / \mathrm{CO}$ ratio violations, it is clear that the EDLE class of faults whenever they happen may be more impactful with high standard deviation in variations compared to the rest. They are followed by EDHE, HTTF, PDs, and LMTTF, respectively. 


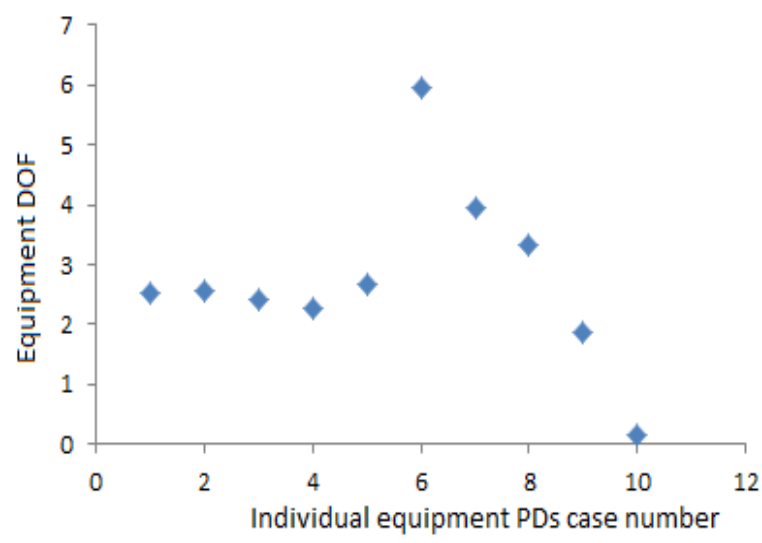

(a) DOF vs. PDs case number

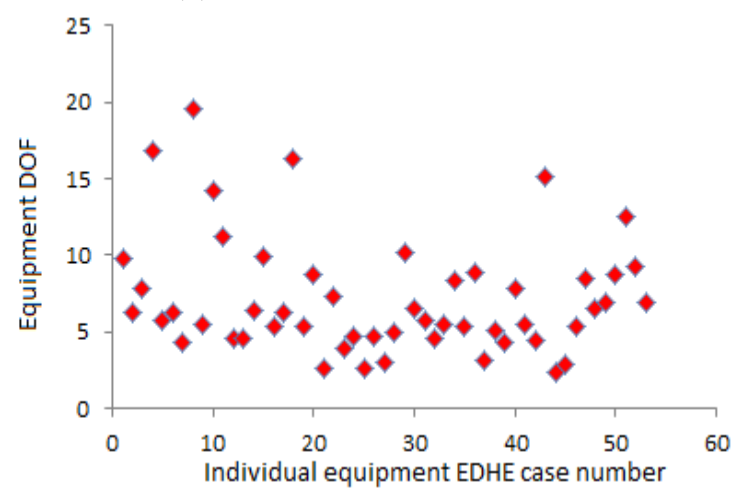

(c) DOF vs. EDHE case number

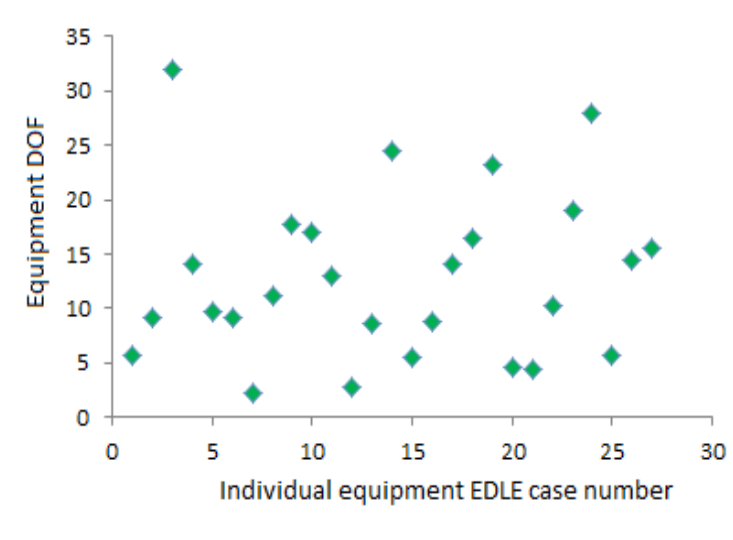

(b) DOF vs. EDLE case number

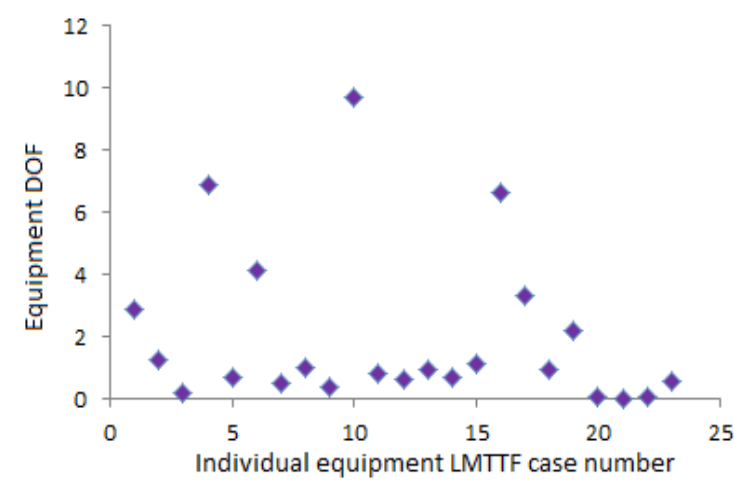

(d) DOF vs. LMTTF case number

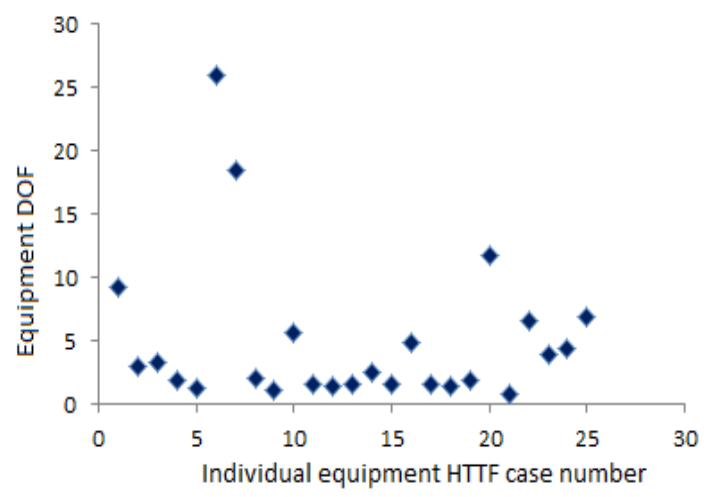

(e) DOF vs. HTTF case number

Figure 11. DOF for various equipment per fault type.

Table 5. DOF statistics for the five classes of faults. PDs: partial discharges.

\begin{tabular}{cccccc}
\hline \multirow{2}{*}{ Statistic } & \multicolumn{5}{c}{ Fault Class } \\
\cline { 2 - 6 } & PDs & LMTTF & HTTF & EDLE & EDHE \\
\hline Mean DOF & 2.760 & 1.989 & 4.934 & 12.830 & 7.071 \\
\hline Standard deviation of DOF & 1.494 & 2.567 & 5.865 & 7.675 & 3.852 \\
\hline Range & 5.814 & 9.699 & 25.192 & 29.695 & 18.508 \\
\hline
\end{tabular}

Table 6 shows 10 cases of EDHE faults DOF as calculated using Equations (9)-(13). From this table, it is clear that the DOF varies from case to case within the same class of fault. 
Table 6. Typical DOF calculated for 10 cases of EDHE [25].

\begin{tabular}{|c|c|c|c|c|c|c|c|c|c|c|c|}
\hline \multirow{8}{*}{ 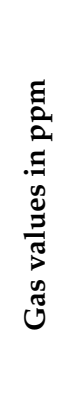 } & Case No. & 1 & 2 & 3 & 4 & 5 & 6 & 7 & 8 & 9 & 10 \\
\hline & $\mathrm{H}_{2}$ & 13500 & 1570 & 3090 & 1820 & 535 & 13 & 137 & 1084 & 34 & 7940 \\
\hline & $\mathrm{CH}_{4}$ & 6110 & 1110 & 5020 & 405 & 160 & 3 & 67 & 188 & 21 & 2000 \\
\hline & $\mathrm{C} 2 \mathrm{H}_{2}$ & 4040 & 1830 & 2540 & 634 & 680 & 6 & 104 & 769 & 56 & 5390 \\
\hline & $\mathrm{C} 2 \mathrm{H}_{4}$ & 4510 & 1780 & 3800 & 365 & 305 & 3 & 53 & 166 & 49 & 3120 \\
\hline & $\mathrm{C} 2 \mathrm{H}_{6}$ & 212 & 175 & 323 & 35 & 16 & 1 & 7 & 8 & 4 & 355 \\
\hline & $\mathrm{CO}$ & 8690 & 135 & 270 & 1010 & 172 & 4 & 196 & 38 & 95 & 1130 \\
\hline & $\mathrm{CO}_{2}$ & 1460 & 602 & 400 & 8610 & 338 & 51 & 1678 & 199 & 315 & 285 \\
\hline \multirow{9}{*}{ 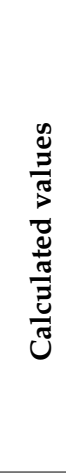 } & $\mathrm{R}_{1}$ & 0.896 & 1.028 & 0.668 & 1.737 & 2.230 & 2 & 1.962 & 4.633 & 1.143 & 1.728 \\
\hline & $\mathrm{R}_{2}$ & 0.453 & 0.707 & 1.625 & 0.223 & 0.299 & 0.231 & 0.489 & 0.173 & 0.618 & 0.252 \\
\hline & $\mathrm{R}_{3}$ & 21.274 & 10.171 & 11.765 & 10.429 & 19.063 & 3 & 7.571 & 20.75 & 12.25 & 8.789 \\
\hline & $\mathrm{R}_{4}$ & 0.168 & 4.459 & 1.482 & 8.525 & 1.965 & 12.75 & 8.561 & 5.237 & 3.316 & 0.252 \\
\hline & $\mathrm{DOF}_{\mathrm{R} 1}$ & 7.958 & 9.281 & 5.684 & 16.37 & 21.295 & 19 & 18.623 & 45.325 & 10.429 & 16.276 \\
\hline & $\mathrm{DOF}_{\mathrm{R} 2}$ & 0 & 0 & 0.625 & 0 & 0 & 0 & 0 & 0 & 0 & 0 \\
\hline & $\mathrm{DOF}_{\mathrm{R} 3}$ & 20.274 & 9.171 & 10.765 & 9.429 & 18.063 & 2 & 6.571 & 19.75 & 11.25 & 7.789 \\
\hline & $\mathrm{DOF}_{\mathrm{R} 4}$ & 16.856 & 0 & 1.025 & 0 & 0.527 & 0.275 & 0 & 0 & 0 & 10.895 \\
\hline & DOF & 11.272 & 4.613 & 4.525 & 6.450 & 9.971 & 5.319 & 6.299 & 16.269 & 5.420 & 8.740 \\
\hline \multicolumn{2}{|c|}{ Fuzzy Logic DOF } & $\mathrm{EF}$ & $\mathrm{F}$ & $\mathrm{F}$ & MF & MF & MF & MF & $\mathrm{EF}$ & $\mathrm{MF}$ & $\mathrm{MF}$ \\
\hline
\end{tabular}

\subsection{Fault Identification}

The fault identification was carried out using the numerical IEC three-gas ratio and two artificial intelligence techniques: fuzzy logic and fuzzy evidential reasoning. One hundred and thirty-eight fault cases of visually inspected and verified equipment found in references $[3,12,25,36]$ were used for verification and comparison among these applied techniques. The outcome is as shown in Tables 7-10. The fault diagnostic carried out in this research was based on four parameters that comprehensively characterize any fault diagnostic method. These parameters are efficacy, fault overlapping cases, unresolved cases, and misdiagnosed cases. An explanation for each case is as given below [8].

(i), Efficacy: sometimes called accuracy and given in percentage, it is the overall number of faults cases correctly identified $\left(\mathrm{N}_{\mathrm{a}}\right)$ divided by the total number of cases under consideration $\left(\mathrm{N}_{\text {total }}\right)$ multiplied by 100, as determined by Equation (55). The higher the efficacy, the better the technique and vice versa.

$$
\text { Efficacy in } \%=\frac{\mathrm{N}_{\mathrm{a}}}{\mathrm{N}_{\text {total }}} \times 100
$$

(ii). Overlapping: this is the ratio of the number of faults that are correctly diagnosed as belonging to a specific fault type $\left(\mathrm{N}_{\mathrm{x}-\mathrm{y}}\right)$ but at the same time appear as a different fault type to the entire number of faults under consideration $\left(\mathrm{N}_{\text {total }}\right)$. The lower the overlap, the better the technique, and vice versa. This is evaluated by Equation (56).

$$
\text { Overlapping in } \%=\frac{\mathrm{N}_{\mathrm{x}-\mathrm{y}}}{\mathrm{N}_{\text {total }}} \times 100
$$

(iii). Unresolved cases: generally, a perfect technique will have zero unresolved cases. This is a scenario where the fault identification technique fails to yield any known fault result. In other words, they are called indeterminate cases. This in the form of a percentage that can be calculated by Equation (57), where $\mathrm{N}_{\mathrm{u}}$ is the unresolved fault cases and $\mathrm{N}_{\text {total }}$ is the sum of all faults examined.

$$
\text { Unresolvedin } \%=\frac{\mathrm{N}_{\mathrm{u}}}{\mathrm{N}_{\text {total }}} \times 100
$$


(iv). Misdiagnosed cases: these are fault cases that are wrongly diagnosed $\left(\mathrm{N}_{\mathrm{m}}\right)$ relative to the entire spectrum of faults $\left(\mathrm{N}_{\text {total }}\right)$ under study. A highly reliable technique ought to have zero misdiagnosed cases. This can be expressed numerically as given by Equation (58).

$$
\text { Misdiagnosedin } \%=\frac{\mathrm{N}_{\mathrm{m}}}{\mathrm{N}_{\text {total }}} \times 100
$$

$\mathrm{N}_{\text {total }}$ is the sum of correctly identified, unresolved and misdiagnosed cases. This is also the number of physically inspected cases given in column two in Tables 7-9.

Table 7. Identification of faults using the IEC60599 technique.

\begin{tabular}{cccccc}
\hline Fault Type & $\begin{array}{c}\text { Number of } \\
\text { Physically } \\
\text { Inspected Cases }\end{array}$ & $\begin{array}{c}\text { Correctly } \\
\text { Diagnosed }\end{array}$ & $\begin{array}{c}\text { Overlapping } \\
\text { Cases with }\end{array}$ & $\begin{array}{c}\text { Unresolved } \\
\text { Cases }\end{array}$ & $\begin{array}{c}\text { Misdiagnosed } \\
\text { Cases as }\end{array}$ \\
\hline PDs & 10 & 9 & 1, LMTTF & 0 & 1, LMTTF \\
\hline LMTTF & 23 & 16 & 3, PDs & 4 & 1, PDs, \\
\hline HTTF & 25 & 17 & 2, HTTF \\
\hline EDLE & 27 & 21 & 10, EDHE & 2 & 1, LMTTF \\
\hline EDHE & 53 & 44 & 17, EDLE & 7 & 2, EDHE \\
\hline Total & $\mathbf{1 3 8}$ & $\mathbf{1 0 7}$ & $\mathbf{3 3}$ & $\mathbf{2 0}$ & $\mathbf{1 1}$ \\
\hline
\end{tabular}

Table 8. Identification of faults using fuzzy logic technique.

\begin{tabular}{cccccc}
\hline Fault Type & $\begin{array}{c}\text { Number of } \\
\text { Physically } \\
\text { Inspected Cases }\end{array}$ & $\begin{array}{c}\text { Correctly } \\
\text { Diagnosed }\end{array}$ & $\begin{array}{c}\text { Overlapping } \\
\text { Cases with }\end{array}$ & $\begin{array}{c}\text { Unresolved } \\
\text { Cases }\end{array}$ & $\begin{array}{c}\text { Misdiagnosed } \\
\text { Cases as }\end{array}$ \\
\hline PDs & 10 & 10 & 0 & 0 & 0 \\
\hline LMTTF & 23 & 19 & 0 & 0 & 3, PDs, HTTF \\
\hline HTTF & 25 & 23 & 0 & 0 & 2, LMTTF \\
\hline EDLE & 27 & 22 & 0 & 0 & 5, EDHE \\
\hline EDHE & 53 & 52 & 0 & 0 & 1, EDLE \\
\hline Total & $\mathbf{1 3 8}$ & $\mathbf{1 2 6}$ & $\mathbf{0}$ & $\mathbf{0}$ \\
\hline
\end{tabular}

Table 9. Identification of faults using fuzzy-evidential reasoning.

\begin{tabular}{cccccc}
\hline Fault Type & $\begin{array}{c}\text { Number of } \\
\text { Physically } \\
\text { Inspected Cases }\end{array}$ & $\begin{array}{c}\text { Correctly } \\
\text { Diagnosed }\end{array}$ & $\begin{array}{c}\text { Overlapping } \\
\text { Cases with }\end{array}$ & $\begin{array}{c}\text { Unresolved } \\
\text { Cases }\end{array}$ & $\begin{array}{c}\text { Misdiagnosed } \\
\text { Cases as }\end{array}$ \\
\hline PDs & 10 & 10 & 0 & 0 & 0 \\
\hline LMTTF & 23 & 20 & 0 & 0 & 1, PDs, \\
\hline HTTF & 25 & 23 & 0 & 0 & 2, LMTTF \\
\hline EDLE & 27 & 23 & 0 & 0 & 4, EDHE \\
\hline EDHE & 53 & 52 & 0 & 0 & 1, EDLE \\
\hline Total & $\mathbf{1 3 8}$ & $\mathbf{1 2 8}$ & $\mathbf{0}$ & $\mathbf{0}$ & $\mathbf{1 0}$ \\
\hline
\end{tabular}

Based on the four parameters characterizing fault identification techniques, the summary of the comparison of each as a percentage of the total 138 fault cases is given in Table 9 for each technique. 
Table 10. Comparison summary in percentages.

\begin{tabular}{ccccc}
\hline Technique & \% Efficacy & $\begin{array}{c}\text { \% Overlapping } \\
\text { Cases }\end{array}$ & $\begin{array}{c}\text { \% Unresolved } \\
\text { Cases }\end{array}$ & $\begin{array}{c}\text { \% Misdiagnosed } \\
\text { Cases }\end{array}$ \\
\hline IEC60599 gas ratios & 77.5 & 23.9 & 14.5 & 8 \\
\hline Fuzzy logic & 91.3 & 0 & 0 & 8.7 \\
\hline $\begin{array}{c}\text { Fuzzy-evidential } \\
\text { Reasoning }\end{array}$ & 92.8 & 0 & 0 & 7.2 \\
\hline
\end{tabular}

\section{Discussion}

From the results of Table 4, one can see that the extent of apparatus healthiness correlates directly with the magnitude of gas quantity generated and TDCG incremental rate. The degree of healthiness quantified by $\mathrm{DOH}$ is a critical variable that requires being evaluated consistently to establish the extent of the facility's health. It can be calculated on a daily basis for vital equipment such as transformers with on-line DGA monitors. This will help assess the aging rate of the insulation system and/or in detecting fault presence. In turn, this information will facilitate the asset manager to make informed decisions when prioritizing resources. A case in hand is during ranking equipment that require maintenance. Equipment manifesting a low degree of health ought to be accorded high significance and vice versa. Similarly, when planning operations, in order for equipment to be fully optimized, only those with a high degree of healthiness should be used. For example, operations acts such as overloading during extreme loads should be discouraged when the $\mathrm{DOH}$ of a transformer lies inside the uncertain region shown in Figure 1.

The DOF analysis has shown that EDLE faults generally are likely to be more serious than the other types of faults with a mean DOF of 12.83 followed at a distance by EDHE at 7.071, then by HTTF at 4.934; HTTF are followed by PDs at 2.76, and lastly are the LMTTF at 1.989. This signifies that electrical faults when they occur are either more faulty (MF) or extremely faulty (EF) compared to the thermal faults that appear to be faulty $(\mathrm{F})$. Therefore, when operating a fault device, the one with an evolving electrical fault may have to be monitored more closely relative to the one with a thermal fault. It should be noted that a $\mathrm{CO}_{2} / \mathrm{CO}$ ratio of less than three may signify oil oxidation, which is a form of chemical faulting. Equally, when this ratio is below three or above 10, it may indicate thermal or electrical faulting involving cellulose. Therefore, this ratio was included just as the Rogers ratios were when calculating the DOF. The DOF is an aggregate of the four ratios weighted equally. The typical DOF of 10 pieces of faulty equipment that suffered EDHE faults have been included in this work as an illustration in Table 6.

Considering the fault identification results shown in Tables 7-10, the numerical technique IEC gas ratios diagnosed 107 faults correctly from the total of 138 cases, which is $77.5 \%$ efficacy. The artificial intelligence fuzzy-evidential reasoning technique has an efficacy of $92.8 \%$; that is, it is able to map 128 faults correctly out of 138 cases. This is much better compared to the former gas ratio method and even the AI fuzzy logic, which has $91.3 \%$ efficacy. Considering all the four parameters for characterizing any fault diagnostic tool, it is clear from Table 10 that for the 138 cases considered, the IEC method has major shortcomings when it comes to overlapping $(23.9 \%)$ and unresolved cases $(14.5 \%)$. It possesses a lot of overlap between electrical discharges of low and high-energy faults. In addition, there is also lots of overlap between low and medium thermal faults and partial discharges faults. Another disadvantage of the IEC gas ratio technique is that it can lead to high indeterminate faults as seen in Table 8 in all fault categories except for PDs, whereas both the AI techniques have zero unresolved cases.

However, it compared fairly well in the misdiagnosed cases $(8 \%)$ with the other techniques at $7.2 \%$ for fuzzy-evidential reasoning and $8.7 \%$ for fuzzy logic. Thus, artificial intelligence techniques such as the fuzzy-ER and FL used in this work have high reliability in fault diagnostics for oil-filled electrical equipment. These two fuzzy methods resemble Duval Triangle 1 and Pentagon 1 regions 
where the six IEC faults are mapped. Thus, their effectiveness will give the same results as those from these two Duval techniques.

Future research will involve searching for more data of visually verified fault cases and old healthy apparatus in order to apply these techniques, enhance them, develop new ones, and compare results with the standard tools that have been documented. It may also include extending the fault identification to biodegradable oil-filled electrical equipment when ample data become available.

\section{Conclusions}

This work has presented a way of synthesizing the DOH and DOF of electrical equipment filled with mineral oil in addition to fault diagnostic study using numerical and artificial intelligence techniques. Results from the evaluation of $\mathrm{DOH}$ has clearly shown its significance especially in applications such as operation, maintenance, and replacement scheduling. It can be recommended using both the magnitude and the incremental rate of TDCG to be taken into consideration if more reliable results of equipment healthiness are to be realized. It has been illustrated that the extent to which the Rogers ratios for healthy equipment have been violated can also be used to quantify the degree of faultiness. These ratios in this work were combined with the $\mathrm{CO}_{2} / \mathrm{CO}$ ratio when violated, since it may be an indication of chemical faulting that they do not capture. This concept of DOF is an alternative to other methods of evaluating fault severity that exist and is flexible, as more faulting aspects of equipment can be added. Then, this information can be used to make an informed decision regarding whether to continue operating the equipment with the fault or not.

An equipment with an $\mathrm{MH}$ between $25 \%<\mathrm{DOH}<75 \%$ or $\mathrm{HH}$ of $\mathrm{DOH}$ of $75 \%$ and above can be overloaded as per manufacturers' guidelines. However, the one with $\mathrm{DOH}<25 \%$ should not be overloaded. Likewise, equipment with a low degree of faultiness, i.e., DOF $<5$, may still be kept in operation pending a planned outage for maintenance but under continuous monitoring. In contrast, that with $5<\mathrm{DOF}<10$ may call for an urgent planned maintenance. Finally, equipment whose DOF $>10$ requires immediate shutdown for maintenance or replacement. The prolonged use of such a facility may lead to a catastrophic failure such as an explosion.

In the fault identification section, the result is explicitly evident that the two artificial intelligence techniques used here are better relative to the IEC60599 and Rogers numerical tools. They possess high efficacy, zero overlap, and zero unresolved cases, which are comparable to those of the Duval Triangle 1 and Pentagon 1 techniques using the six IEC faults. However, both the numerical and artificial intelligence tools have a certain level of misdiagnosed cases; thus, more research for better techniques is still required.

Author Contributions: Conceptualization, methodology, data analysis, and write up; G.K.I.; Conceptualization, validation, data curation, funding acquisition and writing — review and editing; A.O.A. All authors have read and agreed to the published version of the manuscript.

Funding: The APC was funded by Tshwane University of Technology (Republic of South Africa)—Research, Innovation \& Engagement.

Acknowledgments: The authors sincerely acknowledge Tshwane University of Technology for enabling this work materially and Jomo Kenyatta University of Agriculture \& Technology for facilitating one of the author's postdoctoral time off to perform this task.

Conflicts of Interest: The authors would like to state categorically that there is no conflict of interest.

\section{References}

1. Lapworth, J. A novel approach (scoring system) for integrating dissolved gas analysis results into a life management system. In Proceedings of the 2002 IEEE International Symposium on Electrical Insulation, Boston, MA, USA, 7-10 April 2002; pp. 137-144. [CrossRef]

2. Tang, W.H.; Wu, Q.H. Condition Monitoring and Assessment of Power Transformers Using Computational Intelligence; Springer: London, UK, 2011. 
3. Gray, A.R. A Guide to Transformer Oil Analysis, Transformer Chemistry Service. Available online: http://www.satcs.co.za. (accessed on 12 June 2020).

4. Duval, M. Use of Pentagons and Triangles for the Interpretation of DGA in Electrical Equipment. In Proceedings of the TechCon North America Conference Albuquerque, Albuquerque, NM, USA, 23 February 2016; pp. 1-29.

5. Duval, M. State of the Art of Technical Diagnosis through Interpretation of DGA. In Proceedings of the My Transformer Conference 2012, Torino, Italy, 21 November 2012; Available online: http://www.duvalm@ireq.ca (accessed on 24 June 2017).

6. IEEE. Guide for the Interpretation of Gases Generated in Oil-Immersed Transformers; IEEE C57.104-2008; IEEE: Piscataway, NJ, USA, 2009.

7. IEC. Guide on the Interpretation of Dissolved and Free Gases Analysis-Mineral. Oil-filled Electrical Equipment in Service; IEC60599; IEC: Geneva, Switzerland, 2015.

8. Irungu, G.K. Application of Operational Data for Evaluation of Transformer Condition Using Computational Intelligence. D. Tech Dissertation, Tshwane University of Technology, Pretoria, South Africa, November 2017.

9. Arshad, M.; Islam, S.M.; Khaliq, A. Fuzzy logic approach in power transformers management and decision making. IEEE Trans. Dielectr. Electr. Insul. 2014, 21, 2343-2354. [CrossRef]

10. Abu-Saida, A.; Hmood, S.; Islam, S. A new fuzzy logic approach for consistent interpretation of dissolved gas-in-oil analysis. IEEE Trans. Dielectr. Electr. Insul. 2013, 20, 2343-2349. [CrossRef]

11. Gomez, J.A. Experimental Investigations on the Dissolved Gas Analysis, Method through Simulation of Electrical and Thermal Faults in Transformer Oil. Ph.D. Thesis, University of Stuttgart, Stuttgart, Germany, June 2014.

12. Luiz, C.; Duval, M.; Saad, H. Combined Duval Pentagons: A simplified approach. Energies 2020, 13, 2859. [CrossRef]

13. Diaa-Eldin, A.M. Development of a new graphical technique for dissolved gas analysis in power transformers based on the five combustible gases. IEEE Trans. Dielectr. Electr. Insul. 2015, 22, 2507-2512.

14. Guardado, J.L.; Naredo, J.L.; Moreno, P.; Fuerte, C.R. A comparative study of neutral network efficiency in power transformers diagnosis using dissolved gas analysis. IEEE Trans. Power Deliv. 2001, 16, 643-647. [CrossRef]

15. Yang, M.T.; Hu, L.S. Intelligent fault types diagnostic system for dissolved gas analysis of oil-immersed power transformer. IEEE Trans. Dielectr. Electr. Insul. 2013, 20, 2317-2324. [CrossRef]

16. Mehta, A.K.; Sharma, R.N.; Chauhan, S.; Saho, S. Transformer diagnostics under dissolved gas analysis using support vector machine. In Proceedings of the 2013 International Conference on Power, Energy and Control (ICPEC), Sri Rangalatchum Dindigul, India, 6-8 February 2013; pp. 181-186.

17. Wei, C.H.; Tang, W.H.; Wu, Q.H. Dissolved gas analysis method based on novel feature prioritization and support vector machine. IET Electr. Power Appl. 2014, 8, 320-328. [CrossRef]

18. Morais, D.R.; Rolim, J.G. A hybrid tool for detection of incipient faults in transformers based on the dissolved gas analysis of insulating oil. IEEE Trans. Power Deliv. 2006, 21, 673-680. [CrossRef]

19. Yang, H.; Liao, C. Adaptive fuzzy diagnosis system for dissolved gas analysis of power transformers. IEEE Trans. Power Deliv. 1999, 14, 1342-1350. [CrossRef]

20. Bakar, N.A.; Abu-Siada, A.; Islam, S. A Review of dissolved gas analysis measurement and interpretation techniques. IEEE Electr. Insul. Mag. 2014, 30, 39-49. [CrossRef]

21. Duval, M. A review of faults detectable by gas-in-oil analysis in transformers. IEEE Electr. Insul. Mag. 2005, 18, 21-27. [CrossRef]

22. Mharakurwa, E.T.; Nyakoe, G.N.; Akumu, A.O. Power Transformer Fault Severity Estimation Based on Dissolved Gas Analysis and Energy of Fault Formation Technique. Available online: https://www.hindawi. com/journals/jece/2019/9674054/ (accessed on 10 August 2020).

23. Jakob, F.; Noble, P.; Dukarm, J.J. A thermodynamic approach to evaluation of the severity of transformer faults. IEEE Trans. Power Deliv. 2012, 27, 554-559. [CrossRef]

24. Prasojo, R.A.; Gumilang, H.; Suwarno; Maulidevi, N.U.; Soedjarno, B.A. A fuzzy logic model for power transformer faults severity determination based on gas level, gas rate, and dissolved gas analysis interpretation. Energies 2020, 13, 1009. [CrossRef]

25. Duval, M.; de Pablo, A. Interpretation of gas-in-oil analysis using new IEC publication 60599 and IEC TC10 databases. IEEE Electr. Insul. Mag. 2001, 17, 31-41. [CrossRef] 
26. Irungu, G.K.; Akumu, A.O.; Munda, J.L. Transformer condition assessment using dissolved gas analysis, oil testing and evidential reasoning approach. In Proceedings of the 33rd 2015 IEEE Electrical Insulation Conference (EIC), Seattle, WA, USA, 7-10 June 2015; pp. 145-149.

27. US Department of the Interior. Transformer Maintenance; Facilities, Instructions, Standards and Techniques; Bureau of Reclamation, 2000 FIST 3-30; US Department of the Interior: Denver, CO, USA.

28. Emsley, A.M.; Stevens, G.C. Review of chemical indicators of degradation of cellulosic electrical paper insulation in oil-filled transformers. IEE Proc. Meas. Technol. 1994, 141, 324-334. [CrossRef]

29. Tang, W.H.; Spurgeon, K.; Wu, Q.H.; Richardson, Z.J. An evidential reasoning approach to transformer condition assessments. IEEE Trans. Power Deliv. 2004, 19, 1696-1703. [CrossRef]

30. Irungu, G.K.; Akumu, A.O.; Munda, J.L. A new fault diagnostic technique in oil-filled electrical equipment; the dual of Duval Triangle. IEEE Trans. Dielectr. Electr. Insul. 2016, 23, 3405-3410. [CrossRef]

31. Irungu, G.K.; Akumu, A.O.; Munda, J.L. Comparison of IEC60599 gas ratios and an integrated Fuzzy-Evidential reasoning approach in fault identification using dissolved gas analysis. In Proceedings of the 2016 51st International Universities Power Engineering Conference (UPEC), Coimbra, Portugal, 6-9 September 2016; pp. 205-211. [CrossRef]

32. Rakowsky, U.K. Fundamentals of the Dempster-Shafer theory and its applications to systems reliability modeling. Int. J. Reliab. Qual. Saf. Eng. 2007, 14, 579-601. [CrossRef]

33. Yang, B.; Kim, K.J. Application of Dempster-Shafer theory in fault diagnosis of induction motors using vibration and current signals. Mech. Syst. Signal Process. 2006, 20, 403-420. [CrossRef]

34. Fan, X.; Zuo, M.J. Fault diagnosis of machines based on Dempster-Shaffer theory, Part 1: Dempster-Shaffer evidence theory and its improvement. Pattern Recognit. Lett. 2006, 27, 366-376. [CrossRef]

35. Anderson, D.R.; Sweeney, D.J.; Williams, T.A. Statistics for Business and Economics, South-Western Cengage Learning, China, 11th ed.; Cengage: Boston, MA, USA, 2011.

36. Digiorgio, J.B. Northern Technology and Testing 2017. Available online: http://www.nttworldwide.com/ docs/dga2102.pdf (accessed on 9 March 2017).

(C) 2020 by the authors. Licensee MDPI, Basel, Switzerland. This article is an open access article distributed under the terms and conditions of the Creative Commons Attribution (CC BY) license (http://creativecommons.org/licenses/by/4.0/). 